\title{
Modification of Potential Vorticity near the Tropopause by Nonconservative Processes in the ECMWF Model
}

\author{
Elisa Spreitzer, Roman AtTinger, AND MaXi BoetTCHer \\ Institute for Atmospheric and Climate Science, ETH Zürich, Zurich, Switzerland \\ RICHARD FORBES \\ European Centre for Medium-Range Weather Forecasts, Reading, United Kingdom \\ HEINI WERnLI AND HANNA JoOS \\ Institute for Atmospheric and Climate Science, ETH Zürich, Zurich, Switzerland
}

(Manuscript received 1 October 2018, in final form 27 January 2019)

\begin{abstract}
The upper-level potential vorticity (PV) structure plays a key role in the evolution of extratropical weather systems. PV is modified by nonconservative processes, such as cloud latent heating, radiative transfer, and turbulence. Using a Lagrangian method, material PV modification near the tropopause is attributed to specific parameterized processes in the global model of the European Centre for MediumRange Weather Forecasts (ECMWF). In a case study, several flow features identified in a vertical section across an extratropical cyclone experienced strong PV modification. In particular clear-air turbulence at the jet stream is found to be a relevant process (i) for the PV structure of an upper-level front-jet system, corroborating previous observation-based findings of turbulent PV generation; (ii) for the purely turbulent decay of a tropopause fold, identified as an effective process of stratosphere-troposphere exchange; and (iii) in the ridge, where the Lagrangian accumulated turbulent PV modification exhibits a distinct vertical pattern, potentially impacting the strength of the tropopause inversion layer. In contrast, cloud processes affect the near-tropopause PV structure above a warm conveyor belt outflow in the ridge and above cold-sector convection. In agreement with previous studies, radiative PV production dominates in regions with an anomalously low tropopause, where both radiation and convection act to increase the vertical PV gradient across the tropopause. The particular strengths of the Lagrangian diagnostic are that it connects prominent tropopause structures with nonconservative PV modification along the flow and that it quantifies the relative importance of turbulence, radiation, and cloud processes for these modifications.
\end{abstract}

\section{Introduction}

The dynamics of extratropical weather systems are substantially affected by heating and cooling due to diabatic processes, such as cloud latent heat release and radiative transfer, as well as by turbulent mixing and friction. This applies from the mesoscale to the large scale, including fronts (e.g., Parker and Thorpe 1995; Lackmann 2002; Igel and van den Heever 2014), cyclones (e.g., Stoelinga 1996; Rossa et al. 2000; Adamson et al. 2006), and Rossby waves (e.g., Grams et al. 2011; Joos and Forbes 2016). Diagnosing and quantifying the systematic effects

Corresponding author: Elisa Spreitzer, elisa.spreitzer@env.ethz.ch of diabatic processes on the dynamics is subject to ongoing research (e.g., Hardy et al. 2017; Büeler and Pfahl 2017; Crezee et al. 2017; Saffin et al. 2017). Since these processes occur on small scales, they are not explicitly resolved in numerical weather prediction (NWP) models and are instead represented by parameterizations. Uncertainties in these parameterizations significantly contribute to model error in NWP (e.g., Leutbecher et al. 2017).

A useful quantity to concisely describe atmospheric dynamics is, because of its invertibility property, potential vorticity (PV; Hoskins et al. 1985). It is materially conserved under adiabatic and frictionless flow conditions (Ertel 1942), while diabatic heating as well as any 
nonconservative forces cause material changes of PV along air parcel trajectories. From a modeling perspective, all parameterized subgrid processes that alter either temperature or momentum of the resolved flow (in the following termed nonconservative processes) materially modify PV. This property renders $\mathrm{PV}$ a valuable tool in relating subgrid processes to dynamics on the grid scale. Nonconservative processes can modify the PV structure either directly by causing material PV change (direct effect) or indirectly by affecting the flow in the vicinity of materially modified PV (cf. invertibility, "indirect effect"). This study focuses on the direct effect and considers the budget of PV changes along air parcel trajectories. In comparison to investigating instantaneous Eulerian fields, this approach has proven advantageous in explaining the generation of PV anomalies (e.g., Stoelinga 1996; Chagnon et al. 2013; Crezee et al. 2017), since instantaneously created PV anomalies are advected by the flow quickly (e.g., Tory et al. 2012). Other widely used methods to quantify the impact of nonconservative processes on the dynamics include model sensitivity experiments (e.g., Dearden et al. 2016) and PV inversion (e.g., Davis and Emanuel 1991).

The large-scale evolution of the upper-level flow as well as baroclinic development of extratropical cyclones is strongly determined by the near-tropopause PV. The tropopause (here defined as the 2-PVU isosurface; $1 \mathrm{PVU}=10^{-6} \mathrm{~K} \mathrm{~kg}^{-1} \mathrm{~m}^{2} \mathrm{~s}^{-1}$ ) is marked by a sharp isentropic increase of $\mathrm{PV}$ and the isentropic $\mathrm{PV}$ gradient exhibits a large, very localized maximum near the tropopause (Davies and Rossa 1998), which acts as a waveguide for propagating Rossby waves (Martius et al. 2010). This waveguide can be severely influenced by disturbances on its poleward and equatorward side, where the latter typically involve diabatic processes, for instance related to warm conveyor belts (WCBs). These are strongly ascending airstreams in extratropical cyclones that experience intense cloud latent heating (Browning 1986; Wernli and Davies 1997) and have been shown to create upper-level negative PV anomalies in their outflow, both via the "direct effect" and the "indirect effect" (e.g., Pomroy and Thorpe 2000; Grams et al. 2011). Also, longwave radiative cooling, which is typically strong at humidity gradients at the tropopause, can produce PV anomalies there and, for instance, lead to the intensification of tropopause polar vortices (Cavallo and Hakim 2012). Additionally, clear-air turbulence and diffusive mixing are found frequently in the vicinity of the jet stream and upper-level fronts (Jaeger and Sprenger 2007), where these processes can produce PV anomalies and alter the tropopause structure (Staley 1960; Shapiro 1976). By materially changing PV, nonconservative processes also enable stratosphere-troposphere exchange (STE; Stohl et al. 2003). Various studies have identified turbulence (Shapiro 1980), convection (Reid and Vaughan 2004), radiation (Zierl and Wirth 1997), and cloud latent heating (Gray 2006) as relevant processes for STE.

Model studies employing a PV tracer technique revealed that subgrid processes directly impact the structure of near-tropopause PV in NWP models. Chagnon et al. (2013) and Chagnon and Gray (2015) found that a combination of radiative cooling and WCB-related latent heating can produce a dipole of diabatically increased (decreased) PV above (below) the tropopause in troughs related to extratropical cyclones. They emphasized that this near-tropopause effect of diabatic processes may affect Rossby wave propagation. Based on the same technique, Saffin et al. (2017) demonstrated that subgrid processes in an NWP model systematically act to sharpen the vertical PV contrast across the dynamical tropopause. The insight that parameterized processes modify the tropopause is of particular interest in light of findings by Gray et al. (2014), who demonstrated that the isentropic PV gradient at the waveguide systematically decreases with forecast lead time in several NWP models.

The present study assesses the direct impact of subgrid processes on PV near the extratropical tropopause in the state-of-the-art NWP model of the European Centre for Medium-Range Weather Forecasts (ECMWF) using the Lagrangian method introduced by Crezee et al. (2017). The method employs backward trajectories to attribute nonconservative PV changes to specific model parameterizations, which allows for detailed process studies, and is applied to a case study of the flow associated with an extratropical cyclone. The approach relies on a special version of the ECMWF model, which produces output of temperature and momentum tendencies from parameterized physics. The purpose is to identify regions near the tropopause that are affected by the individual model parameterizations, as well as the responsible mechanisms and relevant time scales.

The article is structured as follows. Section 2 provides a description of the diagnostic methods used in this study. It is followed by a synoptic description of the case study in section 3. Section 4 presents a general discussion of the structure of PV modification by nonconservative processes in a vertical section across the cyclone and the associated downstream ridge, while section 5 discusses the role of individual nonconservative processes for selected upper-level PV features and places them into context of previous studies. Finally, in section 6 the results and implications are summarized. 


\section{Methodology}

$\mathrm{PV}$ modification is analyzed in a case study of an extratropical cyclone and the accompanying upperlevel flow. The case is simulated with the Integrated Forecasting System (IFS) of the ECMWF. Lagrangian diagnostics based on offline trajectory calculations are applied to evaluate the role of nonconservative processes for the PV distribution, with a focus on the neartropopause region.

\section{a. Model}

The IFS model version used in this study, cycle 43R1, was operational at the ECMWF from November 2016 to July 2017. The dynamical core of the model is hydrostatic, semi-implicit, semi-Lagrangian, and applies spectral transforms between gridpoint space (where the physical parameterizations and advection are calculated) and spectral space (to solve the governing equations of motion). In the vertical the model is discretized using a finite-element scheme with hybrid pressure-sigma levels (ECMWF 2016a). For the forecast used in this study, the model is run on 137 vertical levels and with a cubic spectral truncation of TCo639, corresponding to a global average horizontal grid spacing of $18 \mathrm{~km}$. The evaluation is based on hourly output fields on model levels, horizontally interpolated to a regular grid with a resolution of $0.25^{\circ}$.

The model includes a set of parameterizations, evaluated in grid space and representing, among others, microphysical processes in large-scale clouds, moist convection, radiation, surface exchange, subgrid-scale turbulent transport, and orographic and nonorographic gravity wave drag. A brief outline of the parameterizations is given below and more details can be found in ECMWF (2016b).

Clouds and large-scale precipitation are parameterized with prognostic equations for cloud liquid, cloud ice, rain, and snow water contents and a subgrid fractional cloud cover (Forbes and Tompkins 2011; Forbes and Ahlgrimm 2014). The scheme is an advanced version of the parameterizations originally developed by Tiedtke (1993). The parameterization of moist convection is based on the mass flux approach and represents deep, shallow, and midlevel (elevated) convection (Tiedtke 1989; Bechtold et al. 2008). The radiation scheme performs computations of the shortwave and longwave radiative fluxes based on the Rapid Radiation Transfer Model (Mlawer et al. 1997; Iacono et al. 2008) and accounts for cloud-radiation interactions using the Monte Carlo independent-column approximation method (Morcrette et al. 2008).

The turbulent diffusion scheme represents the vertical exchange of heat, momentum, and moisture through subgrid-scale turbulence. In the surface layer, it is coupled to the surface-exchange scheme (Viterbo and Beljaars 1995) and the turbulent fluxes are calculated using a first-order $K$-diffusion closure based on the Monin-Obukhov similarity theory. Above the surface layer, in the boundary layer and free troposphere, a $K$-diffusion turbulence closure is used, except for the well-mixed part of unstable boundary layers where an eddy-diffusivity mass flux framework is applied to represent the nonlocal boundary layer eddy fluxes (Siebesma et al. 2007; Köhler et al. 2011). In the free troposphere, the Richardson number-dependent mixing can be significant where there is large vertical shear associated with the upper-tropospheric jet. The turbulent diffusion scheme includes parameterizations to represent turbulent orographic form drag in the lower atmosphere induced by unresolved orography (Beljaars et al. 2004) as well as drag due to orographic flow blocking and absorption and reflection of orographic gravity waves (Lott and Miller 1997). A nonorographic gravity wave drag scheme accounts for the effects of unresolved gravity waves from tropospheric sources such as convection, fronts, and shear zones. This acts as a drag on the flow where the gravity waves break in the stratosphere and mesosphere (Orr et al. 2010).

\section{b. Physical tendencies and PV modification}

The material evolution of PV [i.e., the PV rate (PVR)] is given by (Hoskins et al. 1985)

$$
\mathrm{PVR}=\frac{D}{D t} \mathrm{PV}=\frac{1}{\rho}(\boldsymbol{\eta} \cdot \nabla Q+\nabla \times \mathbf{F} \cdot \nabla \theta),
$$

where $\rho$ is the density of air, $\boldsymbol{\eta}$ the absolute vorticity, $\theta$ the potential temperature, $Q=D \theta / D t$ the diabatic heating, and PV $=(1 / \rho)(\boldsymbol{\eta} \cdot \nabla \theta)$. The three-dimensional vector $\mathbf{F}$ denotes nonconservative forces (i.e., friction, diffusive, and turbulent processes), represented in the IFS by parameterizations.

In addition to the standard output of the IFS simulation, hourly three-dimensional fields of all instantaneous temperature tendencies, $(\partial T / \partial t)_{\text {phys }}$, and tendencies of horizontal wind speed (in the following referred to as momentum tendencies $),(\partial u / \partial t)_{\text {phys }}$ and $(\partial v / \partial t)_{\text {phys }}$, from the parameterized physics are archived. The diabatic temperature tendencies are converted to tendencies of potential temperature, which correspond to the diabatic heating $Q$ in Eq. (1). In the IFS, the parameterized physics only contribute to tendencies (i.e., acceleration and deceleration) of horizontal momentum, $u$ and $v$. Thus we obtain a forcing vector $\mathbf{F}$ with a vanishing vertical component: 


$$
\mathbf{F}=\left(\begin{array}{c}
\partial u / \partial t \\
\partial v / \partial t \\
0
\end{array}\right)_{\text {phys }}
$$

Because Eq. (1) is linear in $Q$ and $\mathbf{F}$, it can be partitioned into a sum of PV tendencies from individual processes. We consider four contributions to the total PV tendency according to the parameterizations as follows: (i) PV tendencies due to heating and cooling from the large-scale cloud scheme, denoted by $\mathrm{PVR}_{\mathrm{ls}}$; (ii) $\mathrm{PV}$ tendencies resulting from temperature and momentum tendencies from the convection scheme, denoted by $\mathrm{PVR}_{\text {conv }}$; (iii) the same for the sum of the vertical diffusion scheme and the parameterizations of drag on the flow due to subgrid orography and nonorographic gravity wave breaking (collectively referred to as turbulence parameterizations), denoted by $\mathrm{PVR}_{\text {turb }}$; and (iv) PV tendencies due to parameterized longwave and shortwave radiative heating and cooling, denoted by $\mathrm{PVR}_{\mathrm{rad}}$. The total PV tendency [Eq. (1)] is given by the sum of the four tendencies: $\mathrm{PVR}_{\text {tot }}=\mathrm{PVR}_{\mathrm{ls}}+$ $\mathrm{PVR}_{\text {conv }}+\mathrm{PVR}_{\text {turb }}+\mathrm{PVR}_{\text {rad }}$. Throughout the remainder of this article, we refer to the physical parameterizations simply as "processes" and, for example, to the effects of the turbulence parameterizations as "effects of turbulence" (analog wording for the other parameterizations).

\section{c. Lagrangian diagnostics}

To explain the origin of PV anomalies and to attain insight into the role of individual processes in modifying PV over a certain time period, we consider the history of air parcels and the accumulated effect of nonconservative processes on the PV of air parcels along their path rather than instantaneous PV tendencies. While Stoelinga (1996), Gray (2006), and Chagnon et al. (2013), for instance, applied a PV tracer technique for this purpose, our method follows the conceptually similar trajectory-based reverse domain filling approach of Crezee et al. (2017).

Backward trajectories are computed offline with the Lagrangian Analysis Tool (LAGRANTO; Wernli and Davies 1997; Sprenger and Wernli 2015), based on hourly wind fields, with starting points on a horizontal grid with $0.25^{\circ}$ spacing, on vertical levels every $10 \mathrm{hPa}$ between 1000 and $150 \mathrm{hPa}$. The starting time of a trajectory $t_{0}$ is the chronologically last point along a backward trajectory. The nonconservative PV tendencies are traced along the trajectories, again based on the hourly output fields. For each point on the three-dimensional trajectory starting grid, we compute three Lagrangian diagnostics: the accumulated PV, the advective PV, and the net change of PV, to be defined in this section. These diagnostics each construct a three-dimensional Eulerian field.
For an air parcel trajectory following the curve $\mathbf{x}(t)$, the accumulated PV (APV) that the air parcel has experienced in the time interval $\left[t, t_{0}\right]$ is given by the integral of instantaneous PV rates along the trajectory,

$$
\operatorname{APV}\left[\mathbf{x}\left(t_{0}\right), t\right]=\int_{t}^{t_{0}} \operatorname{PVR}[\mathbf{x}(\tau), \tau] d \tau,
$$

with $t<t_{0}$ for backward trajectories. This integral is approximated by the sum of all tendencies along the trajectory at discretized hourly time steps $(\Delta t=1 \mathrm{~h})$ :

$$
\operatorname{APV}\left[\mathbf{x}\left(t_{0}\right), t_{n}\right]=\sum_{k=0}^{n-1} \operatorname{PVR}\left[\mathbf{x}\left(t_{k}\right), t_{k}\right] \Delta t,
$$

with $t_{k}=t_{0}-k \Delta t$. APV is computed for each process $\mathrm{i}-\mathrm{iv}$ defined in section $2 \mathrm{~b}$ separately and the budget of the individual APV of each process yields the total accumulated PV:

$\mathrm{APV}_{\text {tot }}=\mathrm{APV}_{\mathrm{ls}}+\mathrm{APV}_{\text {conv }}+\mathrm{APV}_{\text {turb }}+\mathrm{APV}_{\mathrm{rad}}$.

Additionally, the reverse domain filling technique is applied to compute the conserved, advective $\mathrm{PV}\left(\mathrm{PV}_{\mathrm{adv}}\right)$ at each point [similar to the approach by Wirth and Egger (1999)], by projecting the PV value of the air parcel at an earlier time $t$ to the position of the backward trajectory at $t_{0}$ (i.e., the starting point). The PV that has been conservatively advected to the point $\mathbf{x}\left(t_{0}\right)$ in the time interval from $t$ to $t_{0}$ is given by

$$
\mathrm{PV}_{\mathrm{adv}}\left[\mathbf{x}\left(t_{0}\right), t\right]=\mathrm{PV}[\mathbf{x}(t), t] .
$$

This quantity conceptually corresponds to the so-called advection-only PV tracer of, for example, Gray (2006) and Chagnon et al. (2013).

The net change of PV $(\Delta \mathrm{PV})$ is the difference between the absolute PV (i.e., the actual PV field) and the advective PV:

$$
\Delta \mathrm{PV}\left[\mathbf{x}\left(t_{0}\right), t\right]=\mathrm{PV}\left[\mathbf{x}\left(t_{0}\right), t_{0}\right]-\mathrm{PV}_{\mathrm{adv}}\left[\mathbf{x}\left(t_{0}\right), t\right] .
$$

Similarly, the absolute PV equals the sum of the advective $\mathrm{PV}$, the total accumulated $\mathrm{PV}$, and a residual (RES):

$$
\mathrm{PV}=\mathrm{PV}_{\mathrm{adv}}+\mathrm{APV}_{\mathrm{tot}}+\mathrm{RES}=\mathrm{PV}_{\mathrm{adv}}+\Delta \mathrm{PV} .
$$

The left-hand equation corresponds to Eq. (4) of Crezee et al. (2017).

Note that theoretically the residual should vanish and APV should equal $\triangle \mathrm{PV}$ along a trajectory. However, those ideal conditions are not met in model studies, as further discussed in section $4 \mathrm{~b}$. 
(a) PV at $320 \mathrm{~K}$

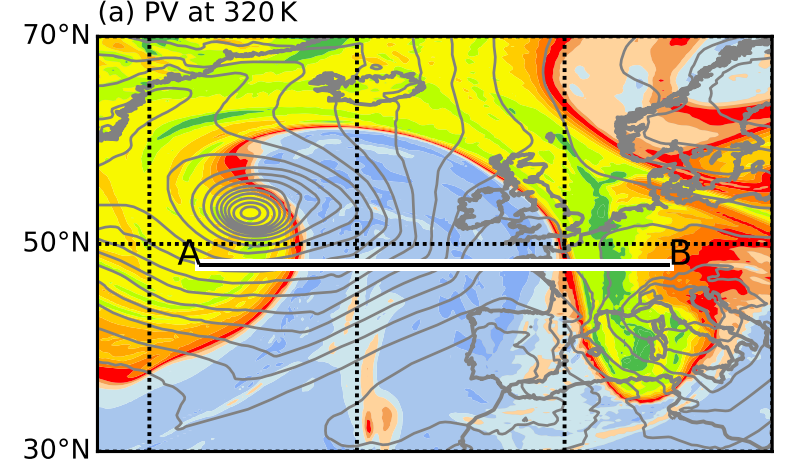

(b) PV at $850 \mathrm{hPa}$

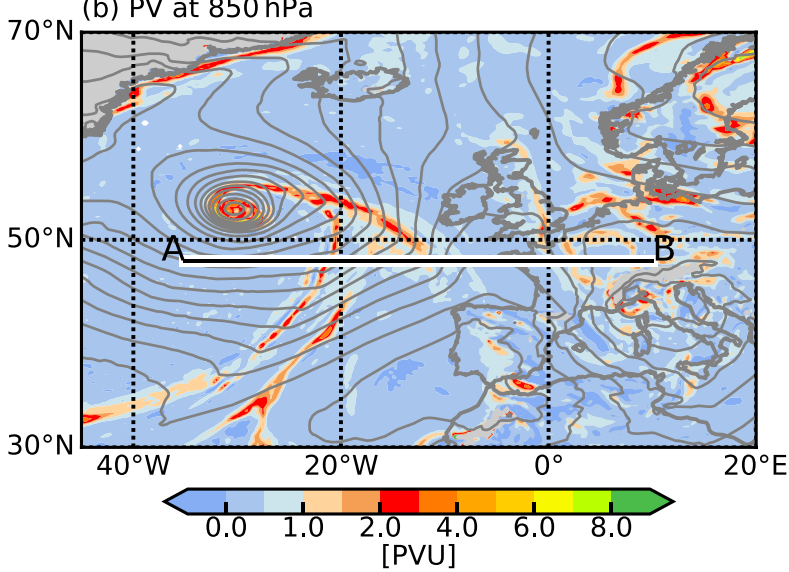

FIG. 1. Synoptic situation at 0000 UTC 6 Feb 2017. (a) PV on the 320-K isentropic level. (b) PV on the 850-hPa pressure level. Gray contours indicate sea level pressure isobars. The black line $\mathrm{AB}$ indicates the location of the vertical cross section discussed in the following sections.

\section{Synoptic description of the case study}

A forecast of a North Atlantic extratropical cyclone was performed, initialized from the ECMWF analysis at 1200 UTC 4 February 2017. From a state of an initially zonal upper-level jet over the North Atlantic, a strong surface cyclone develops off the North American coast, crosses the North Atlantic, and reaches its maximum intensity on 6 February south of Iceland. As the cyclone intensifies, the upper-level trough strengthens, while an upper-level ridge develops downstream, shown by the PV distribution on the 320-K isentropic level (Fig. 1a). The outflow of a WCB associated with the cyclone is located within the ridge (not shown). Downstream, the ridge is flanked by a broad PV streamer extruding into the western Mediterranean. At lower levels, the cyclone exhibits a frontal T-bone structure with a warm front and a cold front perpendicular to each other, both associated with narrow bands of positive $\mathrm{PV}$ anomalies at $850 \mathrm{hPa}$ (Fig. 1b).

In the remainder of the study, the structure of several upper-level PV features and the contribution of nonconservative processes to the evolution of these features are investigated. The case study is evaluated in a zonal cross section south of the cyclone center, along $48^{\circ} \mathrm{N}$ (as indicated by the black line $\mathrm{AB}$ in Fig. 1) at 0000 UTC 6 February 2017 (i.e., $36 \mathrm{~h}$ after the initialization time of the forecast), when the surface cyclone is fully developed and upper-level ridge building has commenced. In the following, this time is referred to as reference time $t_{0}$. The vertical cross section, shown in Fig. 2a, exhibits several upper-level PV features that are representative of the synoptic system at this stage. Similar PV features are commonly found in association with baroclinic waves in general. The western part of the section crosses the upper-level trough where the tropopause is low and slightly folded above the surface cold front. The upper-level ridge appears as an elevated tropopause between $20^{\circ}$ and $5^{\circ} \mathrm{W}$ and is flanked downstream by a northerly $70 \mathrm{~m} \mathrm{~s}^{-1}$ jet streak associated with a strong isentropic PV gradient and a tilted tropopause fold (note that in this cross section the elongated PV filament referred to as tropopause fold is detached from the stratospheric reservoir). The vertical wind shear zones above and below the jet core are characterized by a low Richardson number and exhibit clear-air turbulence (not shown).

\section{PV modification}

\section{a. Net Lagrangian PV change}

The Lagrangian PV diagnostics defined in section 2c depend on the integration time along the trajectories. For the following analysis we choose a backward integration time of $24 \mathrm{~h}$. The nonconservative PV structures we find do not change significantly for longer integration times up to $36 \mathrm{~h}$. A first qualitative assessment of the effect of nonconservative processes on the $\mathrm{PV}$ is made by comparing the absolute PV field at $t_{0}$ (Fig. 2a) and the 24-h advective PV (PV adv; Fig. 2b). For reference, the black contour in Fig. $2 b$ shows the dynamical tropopause (2-PVU contour) with respect to the absolute PV, while the 2-PVU contour of the advective PV field (in the following termed advective tropopause) is indicated in dark red. Overall, the fields of absolute and advective PV are very similar and in most parts of the cross section both tropopause contours match closely. The low- and midlevel PV anomalies associated with the surface fronts are not present in the advective PV field (Fig. 2b), illustrating their purely diabatic origin. Below the trough near $30^{\circ} \mathrm{W}$ and west of the surface cold front, the upper-tropospheric absolute PV is much smaller than the advective PV, leading to an increased vertical PV gradient across the tropopause compared to the advective field. The difference between the actual and the advective tropopause contours indicates that 
(a) Absolute PV
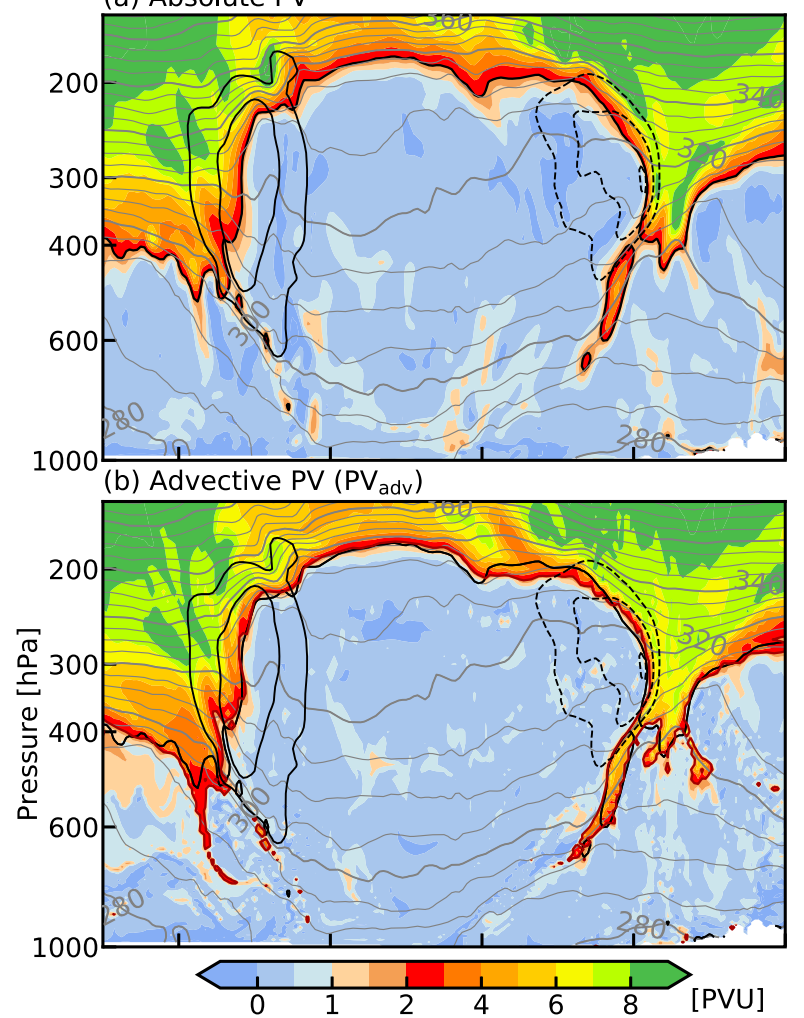

(c) Net PV change $(\triangle P V)$

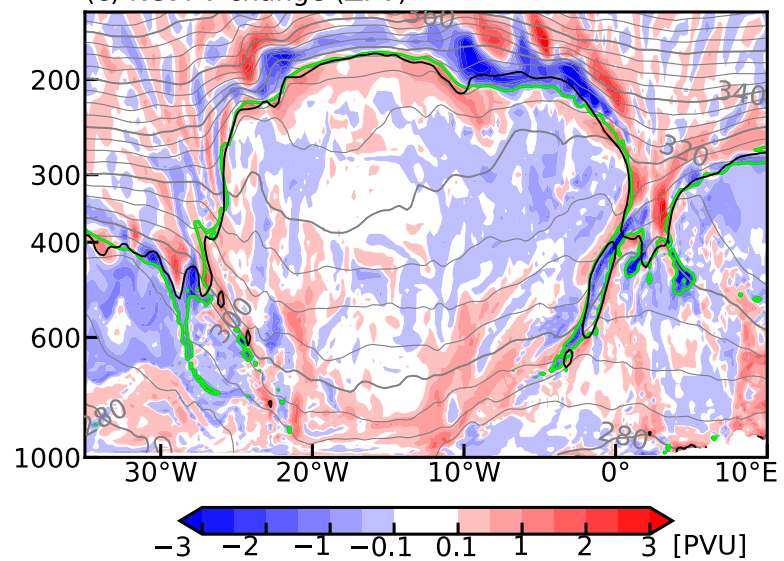

FIG. 2. Vertical cross section at $48^{\circ} \mathrm{N}$ at 0000 UTC 6 Feb 2017. (a) Absolute PV (color shading), the 2-PVU contour (solid black line), and the meridional wind speed (thin black lines; solid northward, dashed southward; intervals of $15 \mathrm{~m} \mathrm{~s}^{-1}$, starting at 40 and $-40 \mathrm{~m} \mathrm{~s}^{-1}$, respectively). (b) 24-h advective $\mathrm{PV}\left(\mathrm{PV}_{\text {adv }}\right.$; color shading), wind contours as in (a), the 2-PVU contour of the absolute PV field (solid black lines), and the 2-PVU contour of the advective PV field (dark red lines). (c) 24-h net PV change ( $\triangle \mathrm{PV}$; color shading), 2-PVU contour of absolute PV field (solid black lines), and the 2-PVU contour of the advective PV field (green lines). The solid gray lines indicate isentropes in all panels.
STE has occurred in this region, since air masses located between the two contours must have crossed the tropopause within the past $24 \mathrm{~h}$. The vertical gradient of the absolute $\mathrm{PV}$ is also increased where the tropopause is low in the streamer east of $0^{\circ}$; here the absolute PV additionally has a local maximum immediately above the tropopause. In contrast, in the eastern part of the ridge the tropopause is sharper in the advective PV. In the downstream tropopause fold, the advective PV values are notably larger than the absolute PV values and the PV filaments are connected to the stratosphere. Additionally, the differences in the PV fields indicate that STE has occurred in the tropopause fold. The tropopause fold is a consistent feature occupying the entire flank of the ridge.

Figure $2 \mathrm{c}$ shows the net PV change, $\triangle \mathrm{PV}$ [Eq. (6)], and highlights regions where PV modification has occurred. In the troposphere, it is mainly positive at lower levels and negative at upper levels. The amplitude of the net $\mathrm{PV}$ change is largest in the vicinity of the tropopause and in the lowermost stratosphere, where it reaches values of up to $3 \mathrm{PVU}$ in $24 \mathrm{~h}$. The relative change of PV, however, is not stronger than at lower levels, since the absolute PV values are much larger. Also note that vertical sections across other parts of the cyclone contain regions in the lower troposphere where $\Delta \mathrm{PV}>3 \mathrm{PVU}$, especially in the cyclone center (not shown). Where the tropopause has a low elevation (in the trough to the west and the streamer to the east of the section), the net PV change tends to exhibit a dipole structure with an increase above and a decrease below the tropopause. Throughout the ridge, a vertical tripole pattern of net PV change is found across the tropopause and in the lowermost stratosphere. This pattern covers the entire ridge north of $45^{\circ} \mathrm{N}$ (not shown). In the stratospheric region on the cyclonic-shear side of the jet streak near $0^{\circ}$, a mesoscale feature with a considerably positive net $\mathrm{PV}$ change is found (also visible as a small positive PV anomaly in the absolute PV field in Fig. 2a), which is consistently present all along the eastern flank of the ridge (not shown).

The Lagrangian PV modification in the aforementioned tropopause features and the involved subgrid processes will be discussed in section 5 .

\section{b. Residual}

As mentioned in section 2c, the total accumulated PV is only an approximation of the net PV change and a residual arises. The 24-h residual PV change [RES $=\Delta \mathrm{PV}-$ $\mathrm{APV}_{\text {tot }}$; Eq. (7)] shown in Fig. 3a, is nonzero for the following reasons: (i) The dynamical core of the model does not explicitly conserve PV. Horizontal diffusion and implicit numerical diffusion in the advection scheme cause 
(a) Residual

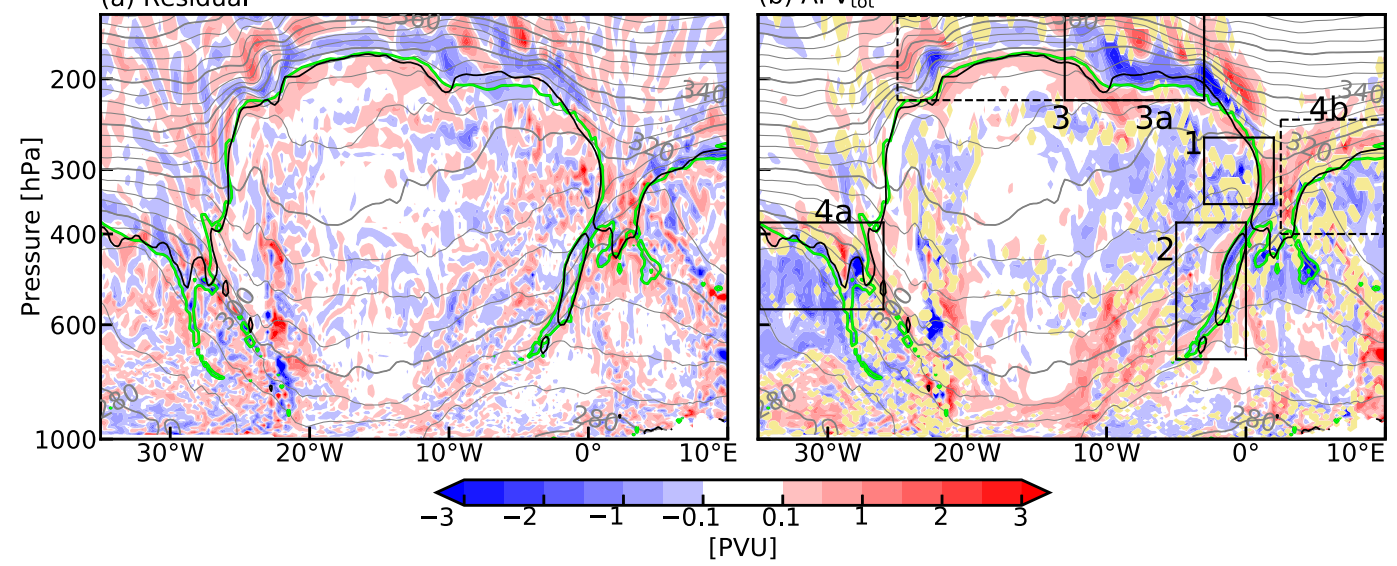

(b) $A P V_{\text {tot }}$

FIG. 3. (a) 24-h residual PV change (net PV change minus total accumulated PV) in the vertical cross section. (b) 24-h total accumulated PV ( $\left.\mathrm{APV}_{\text {tot }}\right)$ with inconsistent grid points masked in yellow. The black boxes 1-4 indicate regions of interest discussed in section 5. Contours are as in Fig. 2c.

PV changes, which are not explicitly captured by our method. Saffin et al. (2016) showed, based on a PV tracer technique, that this nonconservation of PV by the dynamical core can be on the same order of magnitude as the total accumulated PV in the Met Office Unified Model. (ii) Position errors arise in the offline trajectory calculations, based on hourly wind fields, and PV inaccuracies result from linear interpolation. (iii) Related to that, instantaneous physical tendencies at a temporal resolution of $1 \mathrm{~h}$ (archiving time step) are used, so it is implicitly assumed that the three-dimensional fields of the physical tendencies are representative for an entire hour, while the actual model time step is $12 \mathrm{~min}$. This implies that, in our method, the effects of rapidly changing processes on time scales of one hour or less, such as convection and local turbulence, on PV are not necessarily well represented. An air parcel trajectory might, for instance, pass through a grid box where the convection parameterization produces a strong heating tendency at the archiving time step, while the tendencies could have been close to zero for all other internal model time steps of the same hour. Our method would then (falsely) consider the large tendencies to be valid for an entire hour and likely overestimate the effect on PV. The converse situation is also conceivable, where a model time step that is not an archiving time step exhibits strong tendencies, which cause a change to the PV field but are missed by the hourly trajectory and therefore not captured by the Lagrangian diagnostics. The use of model fields archived every $12 \mathrm{~min}$ would presumably lead to reduced trajectory position errors (ii), as well as to reduced errors due to (iii), resulting in a smaller residual.

For the most part, the residual is small and rather noisy (Fig. 3a), but tends to be large at the cold front and near the tropopause. It can reach a similar magnitude as the net PV change, consistent with the results of Saffin et al. (2016). However, our trajectory method does not allow us to quantify individual contributions of the error sources (i-iii).

To obtain robust results in attributing of PV features to specific nonconservative processes in spite of a partially large residual, we apply a simple measure to determine the reliability of the diagnostics at each grid point. The results are only analyzed where both diagnostics, $\triangle \mathrm{PV}$ and $\mathrm{APV}_{\text {tot }}$, are consistent in the sense that they agree in sign and only have an amplitude error. Figure $3 b$ shows APV tot where the two PV diagnostics agree in sign, while all other grid points where the two PV diagnostics are of opposite sign and have a minimum amplitude of $0.1 \mathrm{PVU}$ are masked in yellow. At these grid points the diagnostics are regarded as inconsistent and the associated trajectories are excluded from all following analyses.

\section{c. Process attribution}

Figure 4 shows the contribution of the four parameterized processes introduced in section $2 \mathrm{~b}$ to $\mathrm{APV}_{\text {tot }}$, that is, large-scale cloud (Fig. 4a), convection (Fig. 4b), turbulence (Fig. 4c), and radiation (Fig. 4d), using the same masking scheme for inconsistent grid points as in Fig. 3b. Note that the APV features described in this section are not exclusively relevant for this specific cross section but are fairly consistent throughout the entire system at this stage, as mentioned in sections 3 and $4 a$.

The first-order effect of diabatic heating is to produce positive PV tendencies below and negative tendencies above the level of maximum heating [cf. Eq. (1)]. As a consequence, an ascending WCB with midlevel latent heating from the large-scale cloud scheme generates positive PV tendencies at lower levels and experiences negative PV tendencies at upper levels (e.g., Wernli and 
(a) Large-scale cloud $\left(\mathrm{APV}_{\mathrm{ls}}\right)$

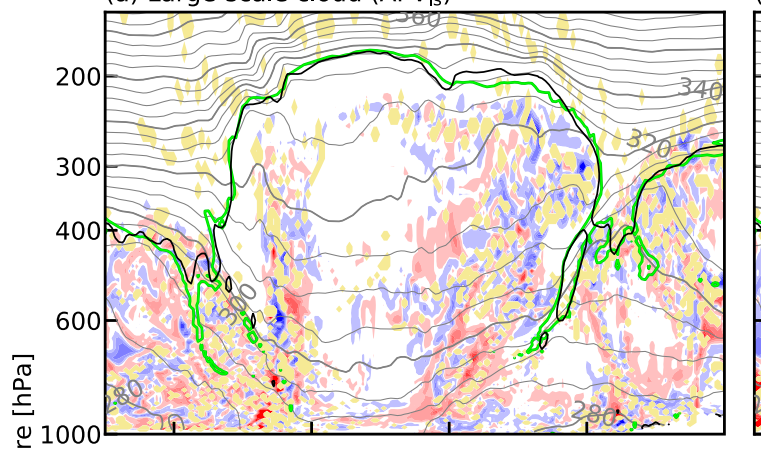

$\begin{array}{lll}\circlearrowleft & \text { (c) Turbulence (APV } & \\ \text { turb }\end{array}$

ญे

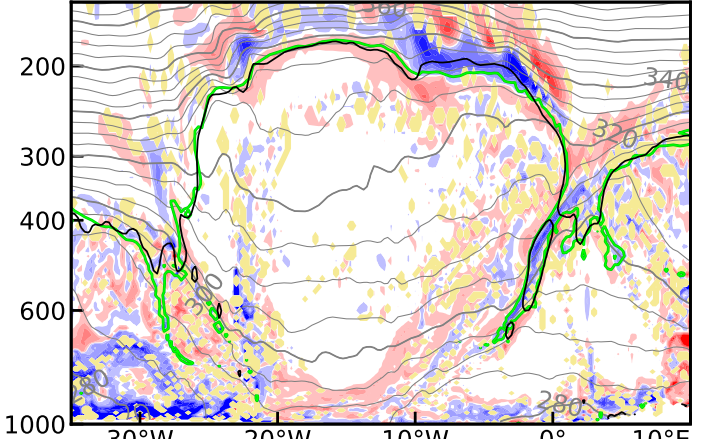

(b) Convection (APV conv)

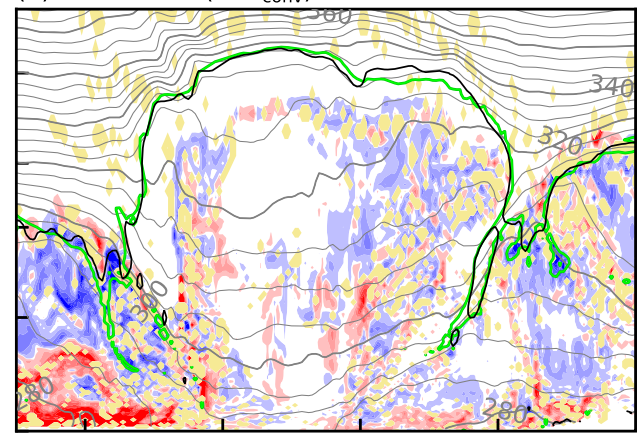

(d) Radiation $\left(\mathrm{APV}_{\mathrm{rad}}\right)$

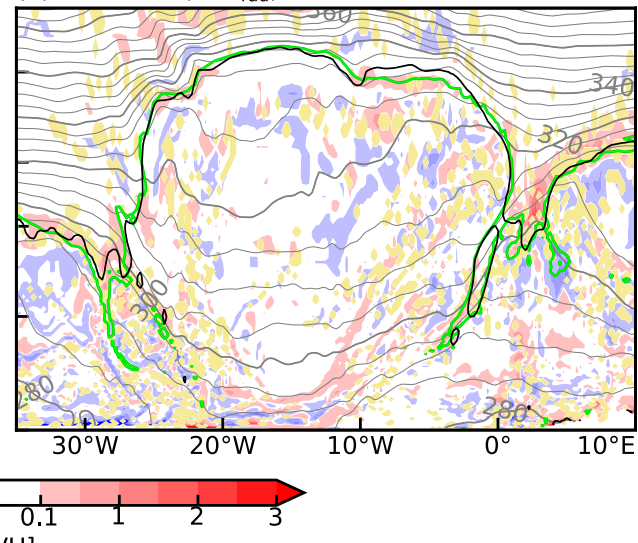

FIG. 4. As in Fig. 3b, but partitioned into contributions from individual processes: (a) large-scale cloud scheme $\left(A P V_{l s}\right),(b)$ convection scheme $\left(A P V_{\text {conv }}\right),(c)$ turbulent processes $\left(A P V_{\text {turb }}\right)$, and (d) radiation $\left(A P V_{\text {rad }}\right)$.

Davies 1997; Joos and Wernli 2012). Thus, mainly positive APV from cloud latent heating is found near the surface fronts (Fig. 4), but similar to Crezee et al. (2017) we observe complex frontal structures of $A P V_{1 s}$. The upper-level $A P V_{\text {ls }}$ exhibits patches of both negative and positive values.

The convection scheme also produces midlevel latent heating, so the effect is similar to that of the large-scale cloud scheme, but is additionally affected by the internal mixing scheme included in the convection parameterization. In addition to the frontal zones, the convective cold sector west of $20^{\circ} \mathrm{W}$ displays large positive $\mathrm{APV}_{\text {conv }}$ in the lower troposphere and large negative values above, up to the tropopause. Convection is thus responsible for the tropospheric PV decrease beneath the trough (mentioned in section $4 \mathrm{a}$ ) and also produces the negative APV below the PV streamer to the east. The IFS parameterization schemes are called sequentially and strong cancellations of APV between the schemes arise. For instance, in the upper troposphere between $25^{\circ}$ and $5^{\circ} \mathrm{W}, \mathrm{APV}_{\mathrm{ls}}$ and $\mathrm{APV}_{\text {conv }}$ compensate each other partially such that the budget yields negative APV (Fig. 3b). Hence, the combined effect of both schemes is to generate negative APV throughout the
WCB outflow in the ridge and thereby enhance the negative PV anomaly on a time scale of $24 \mathrm{~h}$.

The APV due to turbulent processes results from a sum of several tendencies (cf. section 2b). As expected, $\mathrm{APV}_{\text {turb }}$ (Fig. 4c) is large in the boundary layer (mainly behind the cold front, where surface fluxes are large; cf. Vannière et al. 2016), but also throughout the troposphere in the cold sector, where it partially compensates $\mathrm{APV}_{\text {conv. }}$ Turbulence strongly reduces PV at the cold front, while the warm front is mainly associated with positive APV $\mathrm{Aurb}_{\text {tur }}$. At upper levels, zones of vertical wind shear near the jet are important regions of clear-air turbulence and thus instantaneous PV modification by turbulent diffusion. In the tropopause region in the ridge where the tropopause is nearly horizontal, turbulence is the dominant process and responsible for producing the vertical tripole pattern in APV between roughly 250 and $150 \mathrm{hPa}$. In the vicinity of the upper-level front-jet system near $0^{\circ}$, it produces the positive PV anomaly on the cyclonic-shear side of the jet, whereas it is responsible for the PV reduction in the tropopause fold. The upperlevel jet and tropopause region is conducive to the emission of gravity waves (e.g., Plougonven and Zhang 2014). The contribution of the parameterized 
nonorographic gravity wave drag to the upper-level $\mathrm{APV}_{\text {turb }}$ is very small (not shown) and the strongly dominating contribution comes from the vertical diffusion scheme. However, resolved gravity waves may induce turbulence by locally enhancing wind shear and thus tendencies from the vertical diffusion scheme. A substantial role of resolved gravity waves for the generation of the spatially consistent upper-level APV patterns is unlikely, since gravity waves are spatially and temporally highly variable, transient phenomena and the Lagrangian integration of PV tendencies would presumably cancel their effects, especially because of short residence times of air parcels in the vicinity of gravity waves. However, relevant contributions of gravity waves emitted in the jet region cannot be ruled out entirely.

Radiative PV tendencies are usually dominated by longwave radiation (not shown). Longwave radiative cooling peaks where sharp moisture gradients are present, most importantly near the tropopause. There the moisture content rapidly decreases with height, which results in positive PV tendencies above (Forster and Wirth 2000; Ferreira et al. 2016). Cloud-top cooling exhibits localized maxima as well and clouds near the tropopause level can enhance the longwave cooling effect of water vapor (Cau et al. 2005). Shortwave heating partially offsets the effect of longwave cooling. APV $\mathrm{Vad}_{\mathrm{rad}}$ is weakly positive at and just above the tropopause, mainly where the tropopause is low (Fig. 4d), and is enhanced in the streamer over Europe, where clouds reach up to the tropopause (not shown).

\section{Discussion of selected upper-level PV features}

In this section, four upper-level PV features and the nonconservative processes relevant for their evolution are investigated in more detail. The features include the positive PV anomaly on the cyclonic-shear side of the upper-level front-jet system at the downstream flank of the ridge (section 5a), STE in the accompanying tropopause fold (section 5b), the APV tripole pattern in the ridge where the tropopause is nearly horizontal (section $5 \mathrm{c}$ ), and the APV pattern across the tropopause in the upstream and downstream troughs (section 5d).

\section{a. Upper-level frontal zone-jet stream system}

The region of the upper-level frontal zone at the jet streak is marked as region 1 in Fig. 3b. In the cyclonicshear zone on the stratospheric side of the front-jet system near $0^{\circ}$, a narrow, mesoscale positive $\mathrm{PV}$ anomaly with values of up to $10 \mathrm{PVU}$ is present (dark green shading in Fig. 2a), which does not exist in the advective PV field (Fig. 2b). The dominant process in creating this anomaly is turbulence (Figs. 4c, 2c, and 3b), with values of $\mathrm{APV}_{\text {turb }}$ of up to $2 \mathrm{PVU}$ in $24 \mathrm{~h}$. On the tropospheric side farther west, where the WCB outflow is located, APV is predominantly negative (up to - 2 PVU), mainly because of large-scale clouds and convection. APV therefore exhibits a pattern of a horizontal dipole across the tropopause and jet axis.

To estimate the time scale on which the PV modifications occur, the median evolution of several variables along the backward trajectories starting from region 1 (Fig. 3b) are displayed in Figs. 5a and 5b, separately for those with $\Delta \mathrm{PV} \geq 0.1 \mathrm{PVU}$ (Fig. 5a) and those with $\Delta \mathrm{PV} \leq-0.1 \mathrm{PVU}$ (Fig. $5 \mathrm{~b}$ ). Recall that because of our trajectory selection (cf. section $4 \mathrm{~b}$ ) APV has the same sign as $\triangle \mathrm{PV}$. For the positive APV trajectories (Fig. 5a), a consistent strong increase of median $\triangle \mathrm{PV}$ leads to a value of $1.2 \mathrm{PVU}$ after $24 \mathrm{~h}$. The strongest increase of $\triangle \mathrm{PV}$ occurs in the last $6 \mathrm{~h}$, when also the median instantaneous PV tendency (gray dotted line, right axis) is considerably positive, indicating a rather short time scale of PV modification of less than $6 \mathrm{~h}$. Total APV (black solid line) is mainly driven by turbulence (blue), additionally with a weak positive but steady contribution from radiation (orange). Total APV has a lower amplitude than $\triangle \mathrm{PV}$, implying a positive residual that enhances the effect of parameterized turbulence. For the negative APV trajectories (Fig. 5b), total APV reaches values of up to $-0.8 \mathrm{PVU}$ at $t_{0}$. It decreases between $t_{0}-15 \mathrm{~h}$ and $t_{0}-6 \mathrm{~h}$, and stays approximately constant afterward, with large-scale cloud latent heating (green) and convection (red) being the dominant processes. The instantaneous PV rate is negative in this interval, concurrent with a midlevel ascent phase typical of WCBs (cf. Madonna et al. 2014; increasing potential temperature and decreasing pressure; see Fig. 5d) above the level of maximum latent heating (not shown), followed by quasi-horizontal advection (Fig. 5d) of the acquired APV toward the jet. Note that while most negative APV air parcels in region 1 ascend as part of the WCB, some travel above the WCB near the tropopause (not shown).

The configuration with a mesoscale positive PV anomaly on the cyclonic-shear side of the jet in region 1 (Fig. 3c) is similar to the front-jet systems described by Shapiro $(1976,1978)$. Shapiro (1976) suggested a diabatic generation mechanism for this anomaly, resulting from turbulent heat flux, based on observational data. To explain the mechanism, we consider the instantaneous PV modification that acts on the air parcels. Figure $5 \mathrm{c}$ therefore shows the average environment in which the air parcels with positive APV in region 1 (same as in Fig. 5a) experience the maximum PV increase along their trajectory, which occurs on average at $t_{0}-3 \mathrm{~h}$. It is constructed as a composite of cross sections 


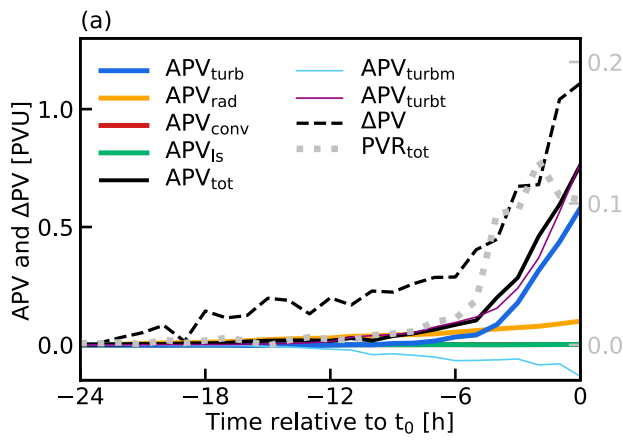

(c)

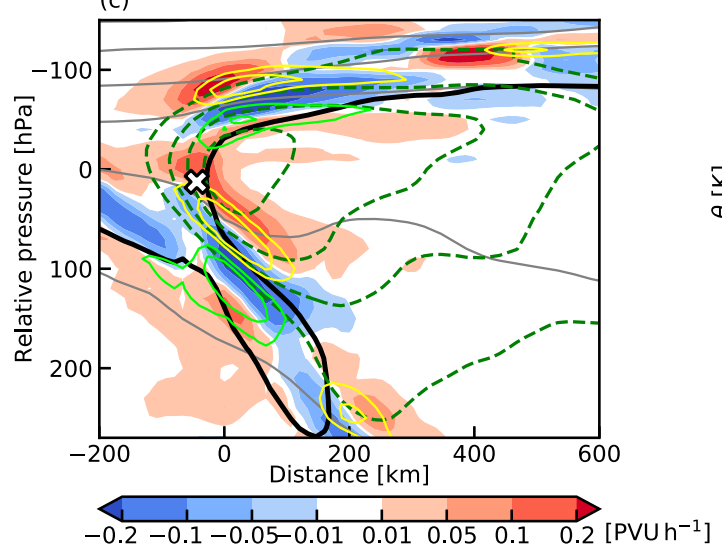

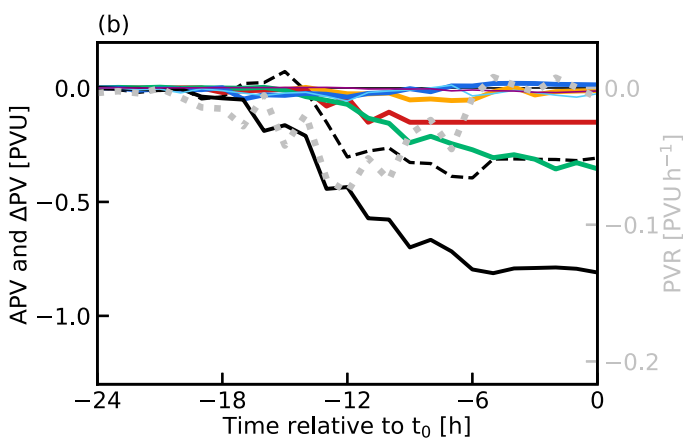

(d)

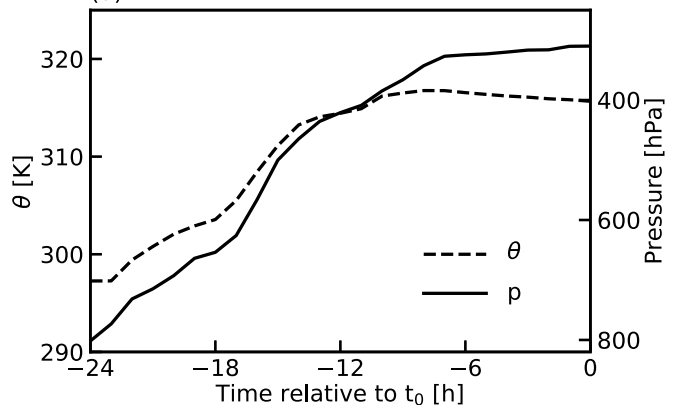

FIG. 5. (a),(b) Temporal evolution of several variables along backward trajectories starting in region 1 (Fig. 3b) and with (a) $\Delta \mathrm{PV} \geq 0.1 \mathrm{PVU}$ and (b) $\Delta \mathrm{PV} \leq-0.1 \mathrm{PVU}$, respectively. The median accumulated PV along the trajectories (APV; accumulation starting at $t_{0}-24 \mathrm{~h}$ ) is partitioned by process (colored lines, with a solid black line for total accumulated PV). The black dashed line indicates the median net PV change $(\Delta \mathrm{PV})$ since $t_{0}-24 \mathrm{~h}$ along the trajectories. The gray dotted line indicates the median total instantaneous PV tendency (PVR; right $y$ axis) along the trajectories. (c) Average environment at the time of maximum PV increase for the same trajectories as in (a), constructed as follows: For each trajectory the time of maximum PV increase (averaged over a moving 3-h window) between $t_{0}-24 \mathrm{~h}$ and $t_{0}$ is selected. At this time step, a cross section at the trajectory position is made, perpendicular to the direction of motion of the associated air parcel. The individual cross sections are centered about the jet core and then averaged to construct the composite (the air parcels move into the drawing plane). Shading indicates the instantaneous turbulent PV tendency $\left(\mathrm{PVR}_{\text {turb }}\right)$, dark green dashed contours depict isotachs (starting at $30 \mathrm{~m} \mathrm{~s}^{-1}$ and plotted every $10 \mathrm{~m} \mathrm{~s}^{-1}$ ), gray solid contours indicate isentropes, the black line depicts the 2-PVU contour, light green (yellow) solid contours indicate diabatic cooling (heating) due to turbulence (starting at $\pm 0.1 \mathrm{~K} \mathrm{~h}^{-1}$ and plotted every $0.1 \mathrm{~K} \mathrm{~h}^{-1}$ ). The white cross shows the mean trajectory position in the cross section. (d) Median potential temperature evolution (dashed line) and pressure evolution (solid line) for the same trajectories as in (b).

perpendicular to the direction of motion, where the air parcel moves into the drawing plane. The color shading indicates the instantaneous turbulent PV tendency

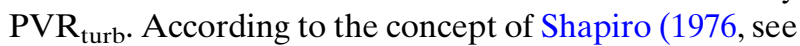
their Figs. 17 and 18), the downward turbulent heat flux is maximized in the areas of strong vertical wind shear (and therefore clear-air turbulence) above and below the jet core, which results in a pattern of potential temperature tendencies as also found in Fig. 5c (thin solid yellow and green contours). On the cyclonic-shear side of the jet, the gradient of these tendencies is directed upward and thus, together with the strong cyclonic shear, generates a positive instantaneous PV tendency. In our case, the average position of the air parcels while experiencing strong PV increase is exactly there (white cross in Fig. 5c). Air parcels traveling in such a flow configuration for several hours accumulate a considerable amount of PV. Note that the air parcels have approximately the same jet-relative position when they experience their PV increase (Fig. $5 \mathrm{c}$ ) as at $t_{0}$, when they arrive in the positive APV area in region 1 (Fig. 3b), because of the short time scale on which the APV is generated. In Fig. 5a, $\mathrm{APV}_{\text {turb }}$ is further split into contributions from the turbulent momentum and temperature tendency, respectively, which reveals that the positive APV is, in line with the mechanism explained above, caused by turbulent temperature tendencies, while the APV from turbulent momentum tendencies is one 
order of magnitude smaller and slightly negative. Shapiro (1976) estimated the effect of turbulent mixing of momentum to be two orders of magnitude smaller than that of turbulent mixing of heat, roughly in agreement with our findings. Altogether, our results presented in Figs. 5a and $5 \mathrm{c}$ confirm that the positive PV anomaly in region 1 (Fig. 3) in our case study was created by the mechanism proposed by Shapiro (1976). While many studies have determined the dry dynamical mechanisms in the development of upper-level frontal zones (e.g., Lang and Martin 2012), these results suggest that diabatic processes are nonnegligible as well. In model sensitivity experiments, Gidel and Shapiro (1979) and Hartjenstein (2000) also found supportive evidence of turbulent mixing causing positive PV anomalies on the cyclonic-shear side of a jet.

Since the maximum of the positive APV is located on the stratospheric side of the front, it tends to enhance the contrast of PV across the 2-PVU surface, with the negative APV from the WCB on the tropospheric side amplifying the effect. Directly at the tropopause the diagnostics are however inconsistent (according to section 4b; see Fig. 3b). The impact of the positive APV on the isentropic PV gradient, and thus the waveguide, is more complex. The band of strong isentropic PV gradients has a typical horizontal width of about $100 \mathrm{~km}$, and so has the positive APV region. Thus, it depends on the exact location of the positive PV anomaly relative to the band whether the PV gradient within the band is diabatically increased or decreased. We leave the impact on the waveguide for future investigation, since the purpose of the present study is to explore the processes and underlying mechanisms altering the PV structure in different regions of the tropopause. This strong diabatic PV modification near the waveguide, associated with an intense jet and a folded tropopause, indicates that errors in the parameterizations of turbulence, large-scale cloud and convection and the related direct PV modification potentially play a role for the too-weak isentropic PV gradients in ridges identified in model forecasts by Gray et al. (2014; see also section 1).

\section{b. Tropopause fold and STE}

The lower part of the tropopause fold associated with the upper-level frontal zone at the downstream flank of the ridge is indicated as region 2 in Fig. $3 b$. Parts of it have been eroded by nonconservative processes within $24 \mathrm{~h}$ such that the PV filament that reaches down to $700 \mathrm{hPa}$ beneath the jet core is locally detached from the stratosphere. The lowermost edge of the filament has been eroded as well, and the remaining PV anomaly is substantially weaker than it would be under conservative conditions (Fig. 2). From the differing positions of the actual tropopause and the advective PV tropopause (e.g., Fig. 2c), it is apparent that STE has occurred in region 2 . The accumulated PV decrease is strongly determined by negative turbulent APV (Fig. 4c).

We evaluate the temporal evolution of the 24-h backward trajectories, starting from region 2, of initially stratospheric air (i.e., with $\mathrm{PV}_{\mathrm{adv}} \geq 2 \mathrm{PVU}$ ). The trajectories experience a quasi-isentropic descent from the stratospheric reservoir to form the tropopause fold (Fig. 6c). PV decreases steadily, with turbulence being the dominant process from $t_{0}-12 \mathrm{~h}$ onward and radiation adding a minor increase to APV (Fig. 6a). The residual is negative, suggesting that $\mathrm{PV}$ nonconservation by the dynamical core and horizontal diffusion might contribute to the decay of the PV anomaly of the tropopause fold. After $24 \mathrm{~h}$, PV within the tropopause fold has decreased by more than 1 PVU on average. Forward trajectories starting from $t_{0}$ to $t_{0}+24 \mathrm{~h}$ show a further decrease of PV, such that all air parcels become tropospheric at the end of the evolution (Fig. 6b). Note that this does not mean that the entire tropopause fold will be eroded at that time, but all air parcels located in the fold at $t_{0}$ cross the tropopause. The instantaneous PV rate (gray dotted line in Fig. 6a) indicates that the strongest PV decrease occurs on a time scale of approximately $18 \mathrm{~h}$.

The turbulent decay of tropopause folds is often discussed as a classical scenario of STE (e.g., Sprenger et al. 2003), especially since folds are regions of strong vertical wind shear and therefore clear-air turbulence. Shapiro (1980) presented observational evidence of turbulent mixing being a relevant mechanism of STE in tropopause folds. Hartjenstein (2000) showed vertical diffusion to be effective in causing the decay of a tropopause fold and associated STE in an idealized model setup; the diffusive PV tendencies in their study exhibit a similar pattern as in our case. Lamarque and Hess (1994) and Gray (2006), on the other hand, identified turbulent mixing as a process contributing to STE in tropopause folds using operational NWP models. However, cloud-diabatic and radiative temperature tendencies were of similar to higher relevance in their respective case studies. Our detailed investigation reveals that parameterized turbulence alone can lead to considerable cross-tropopause mass flux and the decay of a tropopause fold in an operational NWP model.

\section{c. Tropopause region within the ridge}

As mentioned in section 4, in the region of the ridge the net PV change and APV exhibit the structure of a vertical tripole, dominantly produced by turbulence (Fig. 4c), with weakly positive values beneath the advective tropopause, negative values right above the 

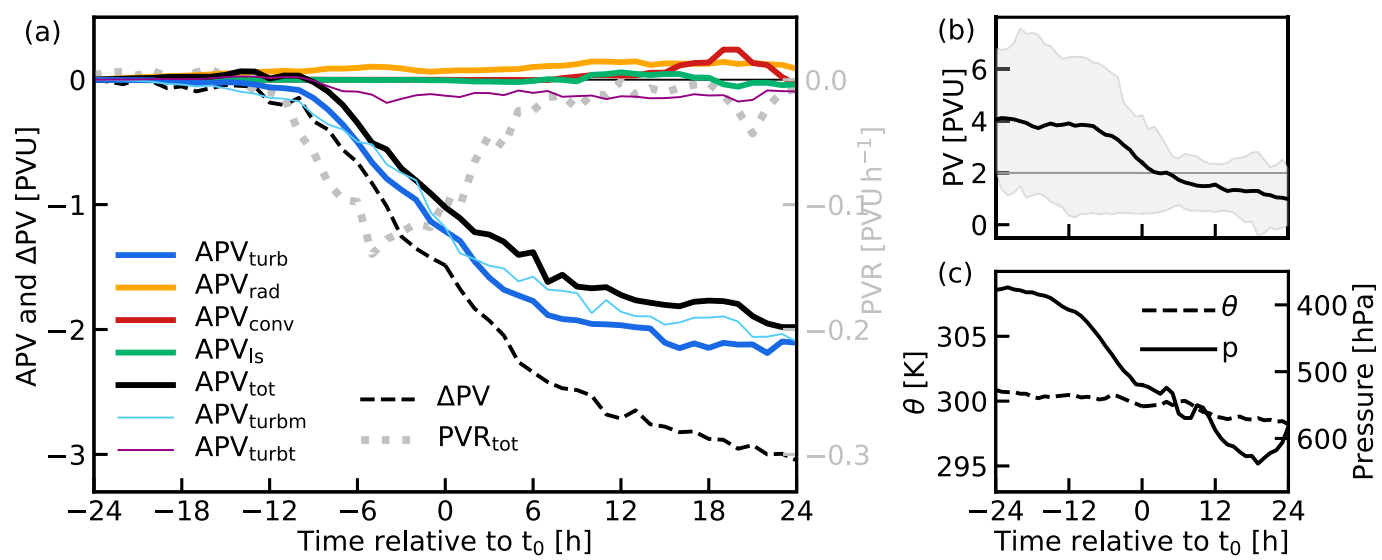

FIG. 6. (a) As in Fig. 5a, but for trajectories starting in region 2 and with $\mathrm{PV}_{\mathrm{adv}} \geq 2 \mathrm{PVU}$. The temporal evolution is extended to the 24-h period after $t_{0}$. (b) Evolution of median PV along the trajectories with gray shading spanning from the minimum to the maximum values. (c) Evolution of median potential temperature (dashed) and pressure (solid).

advective tropopause, and again positive values about $50 \mathrm{hPa}$ above the tropopause. Region 3 in Fig. $3 \mathrm{~b}$ encompasses this tripole. It is remarkable that even regions farther away from the strong vertical shear zones near the jet core are affected by turbulent PV modification. In the eastern part, a slight shift between the advective and the actual tropopause indicates that $\mathrm{PV}$ erosion (negative APV) resulted in STE.

Figures $7 \mathrm{a}-\mathrm{c}$ show the temporal evolution of backward trajectories originating from the eastern part of the ridge (region $3 \mathrm{a}$ in Fig. 3b). The trajectories are split into three sets, starting from the regions with positive APV in the stratosphere (Fig. 7a), negative APV (Fig. 7b), and positive APV in the troposphere (Fig. 7c). Total APV follows the turbulent APV closely in all three trajectory sets. Radiation has a very small negative contribution to the upper positive APV and a minor positive contribution to the lower positive APV in the considered 24-h period. Since region $3 \mathrm{a}$ is rather large and characterized by wind shear, the trajectories do not constitute a coherent airstream and experience their PV change at a wide range of different times. Most air parcels experience their maximum PV increase or decrease between 6 and $18 \mathrm{~h}$ prior to $t_{0}$, near the southwesterly jet at the upstream flank of the ridge or the westerly jet near the axis of the ridge. Figure $7 \mathrm{~d}$ indicates the position of the backward trajectories at $t_{0}-12 \mathrm{~h}$, colored according to the instantaneous turbulent PV tendency they are experiencing at that time, illustrating that considerable PV modification already occurs upstream. The amplitude of the instantaneous turbulent PV tendencies averaged between 320 and $360 \mathrm{~K}$ (gray shading) indicates that turbulent PV modification occurs in a banded region above the jet stream.
The typical environment where the air parcels from region 3a experience strong turbulent PV modification is shown in a composite cross section at the time of maximum PV change in Fig. 7e (constructed in the same way as Fig. 5c). The average position of the trajectories at the time of PV modification is indicated for each set of trajectories by a cross. The vertical tripole pattern of the instantaneous turbulent PV tendency above the level of maximum wind resembles the APV pattern observed in region 3. This indicates that the air experiences turbulent PV modification in zone of vertical wind shear above the jet $\left(>60 \mathrm{~m} \mathrm{~s}^{-1}\right)$. After leaving the shear zone, the air is advected across the ridge, where the influence of turbulence is weaker, and the vertical tripole pattern of the instantaneous PV tendency is approximately retained in APV, albeit with the strongest amplitudes near the shear zones. Note that the potential contribution of gravity waves emitted at the jet to the turbulent PV tendencies in this region cannot be determined by our method; it is however assumed to be most likely negligible (cf. section 4c).

The pattern of APV turb around and above the tropopause in region 3 roughly agrees with findings by Saffin et al. (2017) in their systematic analysis of direct PV modification in the Met Office Unified Model. They observed negative accumulated PV from turbulent mixing with a minimum just below the tropopause and positive accumulated turbulent PV about $1 \mathrm{~km}$ above the tropopause, producing a dipole (see their Figs. $2 \mathrm{c}$ and $7 \mathrm{c}$ ).

Since the emerging regions of net PV change due to turbulence take a rather broad and shallow shape, it is likely that they are primarily associated with static stability anomalies. Thus, they possibly have an impact on the strength and the position of the tropopause inversion 


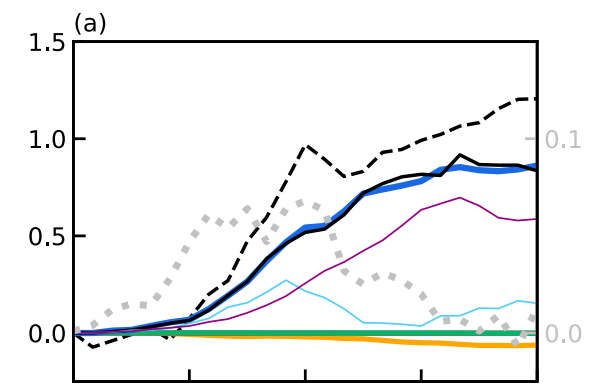

(b)

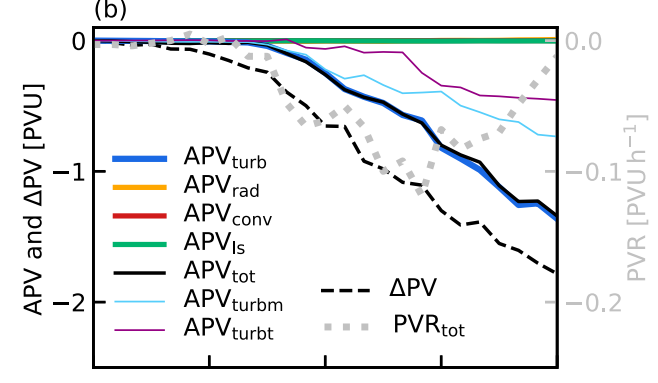

(c)

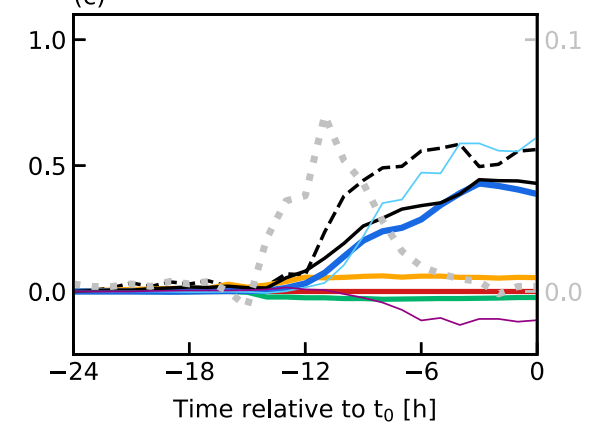

(d)

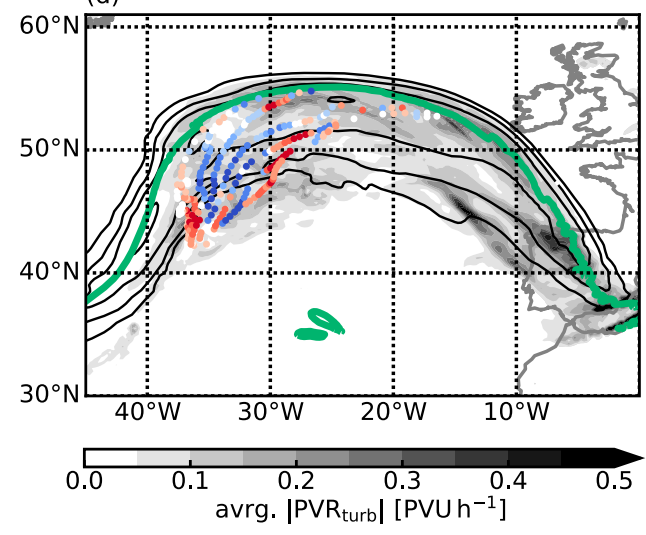

(e)

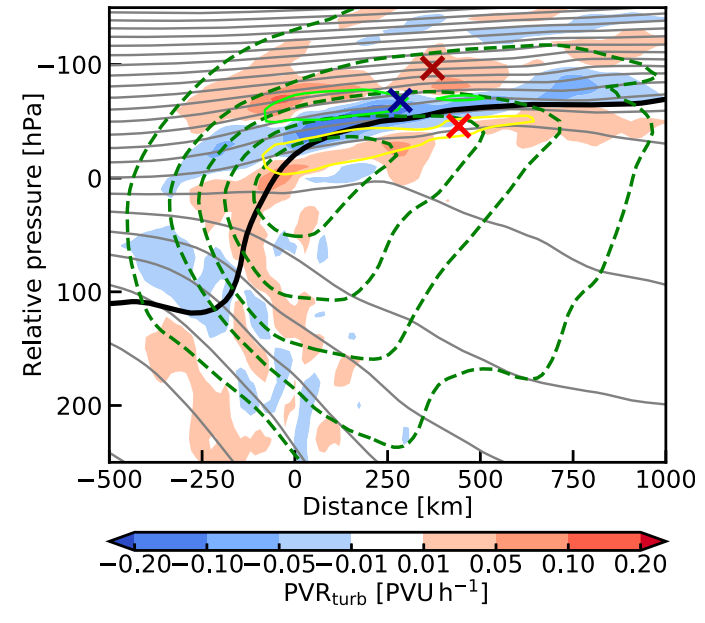

FIG. 7. (left) As in Fig. 5a, but for trajectories starting in region 3a and belonging to (a) the upper positive APV, (b) the negative APV, and (c) the lower positive APV. The threshold for trajectory selection is $|\Delta \mathrm{PV}| \geq 0.1$ PVU. (d) Trajectory positions at $t_{0}-12 \mathrm{~h}$ (dots), colored according to instantaneous turbulent PV tendency (PVR turb $_{\text {turb }}$ at that time. The black contours indicate absolute wind speed at $320 \mathrm{~K}$ (every $10 \mathrm{~m} \mathrm{~s}^{-1}$, starting at $50 \mathrm{~m} \mathrm{~s}^{-1}$ ), the 2-PVU contour at $320 \mathrm{~K}$ is indicated in green, and gray shading shows the absolute value of $\mathrm{PVR}_{\text {turb }}$, averaged between 320 and $360 \mathrm{~K}$. (e) As in Fig. 5c, but for backward trajectories starting in region 3a. The mean position of the trajectories at the time of the cross sections is indicated by the light red cross for the lower positive APV, the blue cross for the negative APV and the dark red cross for the upper positive APV. (right) The lower color bar is valid for both (d) and (e).

layer (TIL; Birner et al. 2002). Assessing their effect on the TIL is not obvious as it depends on the position of the TIL relative to the identified APV pattern. It can result in a strengthening, weakening, or shift of the TIL. Kunkel et al. (2016), for instance, found that parameterized turbulence decreases the strength of the TIL in an idealized baroclinic channel model.

\section{d. Tropopause at low elevations}

Vertical dipoles of net PV change and APV across the tropopause are present where the tropopause is low in the upstream trough (region 4a in Fig. 3b) and on the eastern flank of the downstream PV streamer (region $4 \mathrm{~b}$ in Fig. 3b). Positive APV above the tropopause is more pronounced and broader in region $4 \mathrm{~b}$, while negative APV in the upper troposphere is stronger in region 4a. Unfortunately, our diagnostics are not consistent in a narrow region around the tropopause at the node of the dipole (Fig. 3b) in both regions. The negative APV in the troposphere is dominated by convection with some contributions from the other three processes (Fig. 4). Longwave radiation produces consistent positive APV above the tropopause and dominates the positive pole.

Figure 8 shows the temporal evolution of several variables along backward trajectories starting from region $4 \mathrm{a}$ in the troposphere (Fig. $8 \mathrm{a}$ ) and the stratosphere (Fig. 8b), respectively. Additionally, the temporal evolution of mean vertical profiles along the trajectories 

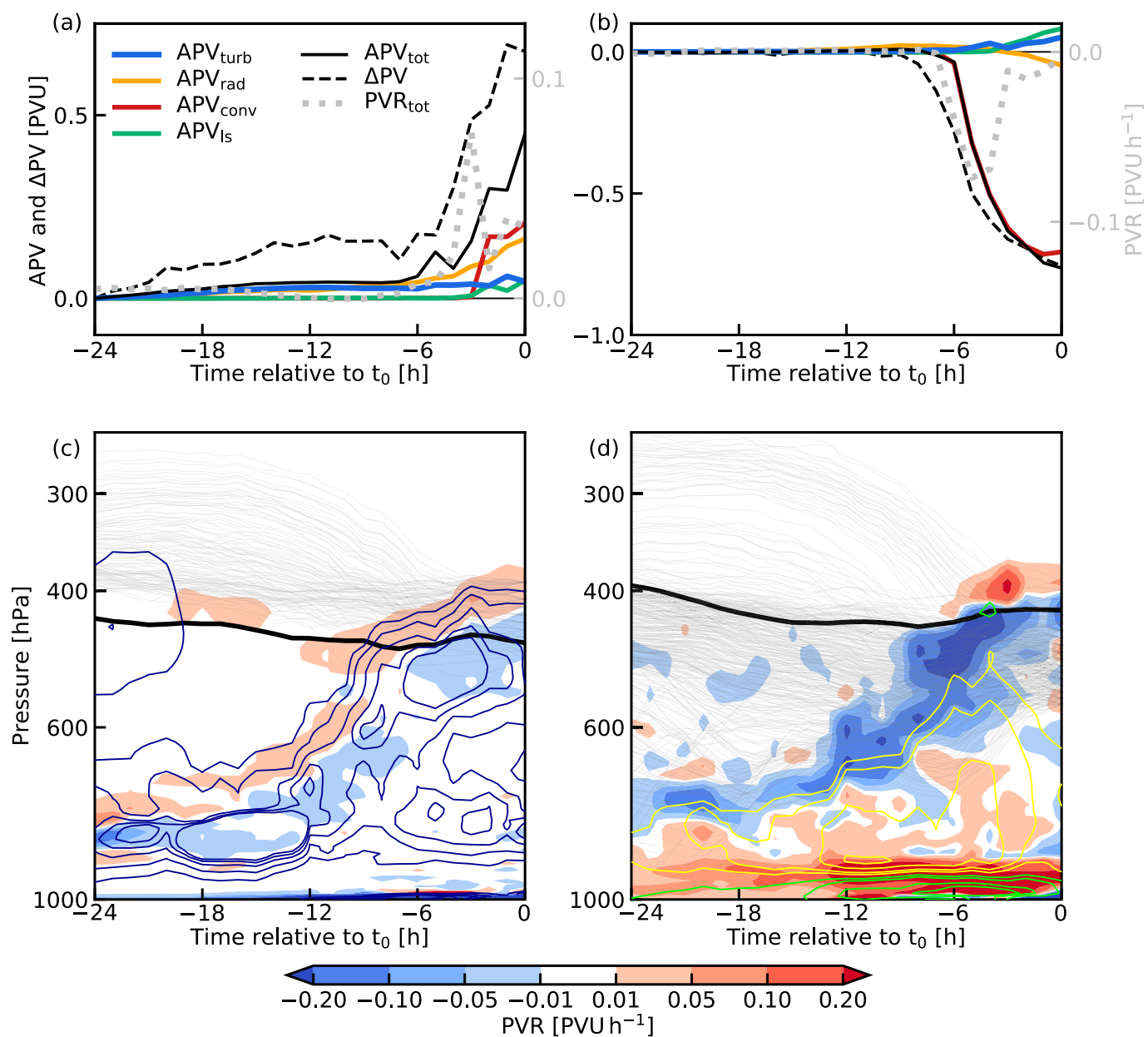

FIG. 8. Temporal evolution along backward trajectories. (top) As in Fig. 5a, but for trajectories starting in region $4 \mathrm{a}$ in (a) the stratosphere and (b) the troposphere. (bottom) Temporal evolution of the mean vertical profiles along backward trajectories: (c) same trajectories as in (a) and (d) same trajectories as in (b). Color shading indicates instantaneous PV rates due to (c) longwave radiation and (d) convection. The blue contours in (c) show liquid water content plus ice water content $\left(2,5,10,15\right.$, and $\left.20 \mathrm{~g} \mathrm{~kg}^{-1}\right)$. The yellow and green contours in (d) respectively show instantaneous heating and cooling due to convection $\left( \pm 0.25,0.5,1.0\right.$, and $\left.1.5 \mathrm{~K} \mathrm{~h}^{-1}\right)$. The solid black line shows the 2-PVU surface, and the thin gray lines indicate the height of the individual backward trajectories in both (c) and (d).

is shown in Figs. 8c and 8d. Convection contributes to positive APV in the stratosphere within the last $3 \mathrm{~h}$ of the evolution, while the PV increase due to radiation is steadily positive over the period (Fig. 8a). The stratospheric trajectories (Figs. 8a and 8c) travel right above the tropopause, constantly experiencing positive radiative PV tendencies, which are increased above clouds reaching up to the tropopause (blue contours in Fig. 8c). The tropospheric trajectories (Figs. $8 \mathrm{~b}$ and $8 \mathrm{~d}$ ) are advected over strong convective heating in low- and midlevel clouds and, at around $t_{0}-6 \mathrm{~h}$, they start rapidly losing PV. Part of the tropospheric trajectories ascend in and above this cold sector convection; another part is advected horizontally near the tropopause, and the initially stratospheric part of the trajectory ensemble descends across the tropopause. A localized positive convective $\mathrm{PV}$ tendency $\left(\mathrm{PVR}_{\text {conv }}\right)$ is found above the tropopause because of overshooting convection (Fig. 8d), which causes the rapid increase of convective APV in the stratospheric set of trajectories within the last $3 \mathrm{~h}$ (Fig. 8a). Note that the positive convective PVR in the stratosphere is qualitatively also found in the vertical profiles of the stratospheric trajectories, but not shown in Fig. 8c. Since both sets of trajectories are more or less vertically aligned in the last few hours before $t_{0}$, the vertical profile of the convective PV rate in Fig. $8 \mathrm{~d}$ is representative of both sets during that time.

Backward trajectories from region $4 \mathrm{~b}$ behave similar to those from region $4 \mathrm{a}$, with a more pronounced contribution from radiation to the stratospheric positive 
APV (since there is more cloud water content near the tropopause in that region). The convective PV tendencies in the troposphere occur earlier and at lower levels along the trajectories, which afterward ascend isentropically to the tropopause, transporting the negative APV signal there (not shown).

The diabatically generated APV dipole across the tropopause in our case study is similar to what Chagnon et al. (2013) and Chagnon and Gray (2015) found in simulations with the Met Office Unified Model, and agrees with the systematic finding of Saffin et al. (2017) that parameterized physical processes sharpen the tropopause in troughs. As discussed by Chagnon et al. (2013), the vertical APV dipole acts to enhance the PV anomalies of an upper-level wave and therefore may support westward wave propagation as well as moist baroclinic growth of a low-level wave. The vertical profiles of moisture and clouds are highly variable, strongly influence the dipole characteristics (this is one reason why it is more pronounced in troughs than in ridges; see also Forster and Wirth 2000; Chagnon and Gray 2015), and can lead to substantial case-to-case variability of the relative role of physical processes for the generation of the dipole. Dyroff et al. (2015) found a systematically too-weak moisture gradient across the tropopause in ECMWF forecasts and analyses compared to observations, possibly related to misrepresentation of such APV dipoles in the model.

\section{Summary and conclusions}

A Lagrangian reverse domain filling method, following the approach introduced by Crezee et al. (2017), was employed to investigate upper-level nonconservative PV modification and to attribute it to specific parameterized subgrid processes in the ECMWF model. In a case study of a wintertime extratropical cyclone, the nonconservative effects on several selected upper-level PV features that typically emerge in baroclinic wave life cycles were analyzed in detail. In agreement with previous studies using a complementary technique (Chagnon et al. 2013; Saffin et al. 2017), PV in the tropopause region was found to be strongly affected by nonconservative processes, accumulated along the flow during the previous $24 \mathrm{~h}$, with net Lagrangian PV changes of up to 3 PVU.

The specific main findings from the Lagrangian PV modification diagnostic applied to four selected neartropopause features, which were identified in a single vertical cross section, can be summarized as follows:

(i) Turbulence produced a mesoscale positive PV anomaly on the stratospheric side of a $70 \mathrm{~m} \mathrm{~s}^{-1}$ jet streak in an upper-level front-jet system, while large-scale cloud and convective processes enhanced the negative PV anomaly on the tropospheric side.

(ii) A deep tropopause fold extending from 400 to $700 \mathrm{hPa}$ associated with the frontal system experienced substantial turbulent decay within $24 \mathrm{~h}$.

(iii) The net nonconservative PV change in an upper-level ridge exhibited a vertical tripole pattern, caused by turbulence mainly in the intense upstream jet.

(iv) In troughs, PV modification led to a vertical dipole of predominantly positive net PV change above the tropopause mainly because of radiation and negative PV change below mainly because of convection.

These findings are relevant, first, for understanding the PV structure in upper-level fronts, as they confirm the observation-based paradigm of turbulent generation of PV anomalies on the cyclonic-shear sides of jets (Shapiro 1976). The same results also imply a possible effect of parameterized turbulence on the waveguide and forecast uncertainties of isentropic PV gradients (Gray et al. 2014). Second, the results illustrate the key role of turbulence for the erosion of tropopause folds and associated efficient stratosphere-troposphere exchange of air. Third, our study indicates that turbulence might be essential for the formation and modification of the tropopause inversion layer in upper-level ridges. While turbulence typically acts on short time scales and locally in shear zones near the upper-level jet, the signal of accumulated PV modification can be transported away from turbulent regions and affect areas that are not characterized by strong turbulence. This reveals that nonconservative processes that occur near jet systems, typically characterized by a vertical tropopause, can also affect the PV structure of regions with a mainly horizontally oriented tropopause.

Our results thus suggest that turbulence in synoptic conditions exhibiting a strong jet, as for instance associated with baroclinic development, is a key process for the modification of PV in several regions of the tropopause. Radiative PV modification is also observed near the tropopause, but is in contrast to turbulence a slow process acting weakly but homogeneously on large areas. Therefore, it has the potential to yield dominating contributions to the PV budget in domain averages [as, e.g., found by Saffin et al. (2017)], especially when considering longer time scales. Since radiative cooling is driven by moisture gradients and clouds, it is more pronounced in low-tropopause regions, for example, in deep troughs and the PV streamers, where it, in conjunction with the convection scheme, can generate vertical PV modification dipoles, which can in turn influence Rossby wave propagation (Chagnon et al. 2013). Convection and large-scale cloud diabatic 
processes additionally enhance the upper-tropospheric negative PV anomaly within the ridge and were also found to potentially impact the PV structure of the upper-level front, as the accumulated diabatic PV signal is transported close to the jet by a WCB.

Since all NWP models rely on different physical parameterizations, it is insightful to examine the direct effects of subgrid processes on PV in each model individually. Our ECMWF model study is in line with several investigations based on the PV tracer technique in the Met Office Unified Model, in particular the observation of the vertical dipole in troughs (Chagnon and Gray 2015), the role of the WCB in producing PV anomalies (Chagnon et al. 2013), and the vertical structure of accumulated turbulent PV near the tropopause in ridges (Saffin et al. 2017). Our trajectory-based approach additionally allows for detailed process studies, as the trajectories provide information on when, where and under which specific conditions PV modification occurs. The same method can also be applied to examine low-level PV features in weather systems, including a detailed attribution of the formation of PV anomalies in cyclones and along fronts to individual cloud-microphysical processes. Our results are only based on a single cross section in one extratropical cyclone. A systematic investigation of the features and processes described in this study is crucial to more robustly quantify the effects of nonconservative processes on PV in the IFS model and will be subject to future research. Additionally, IFS sensitivity experiments and ensemble forecasts of one or more case studies would provide further insight into the role of nonconservative processes on the circulation.

Acknowledgments. We acknowledge the use of the ECMWF's computing and archive facilities in the framework of the special project "Diabatic effects in mid-latitude weather systems" and thank MeteoSwiss for providing access to the ECMWF system. RA and MB acknowledge funding from the Swiss National Science Foundation (Project 165941). We thank Michael Sprenger for helpful discussions on stratosphere-troposphere exchange and for providing our analysis tools, and Carsten Maas for his support with the ECMWF computing facilities. Furthermore, we thank three anonymous reviewers for their encouraging feedback and valuable comments that helped to improve the manuscript.

\section{REFERENCES}

Adamson, D. S., S. E. Belcher, B. J. Hoskins, and R. S. Plant, 2006: Boundary-layer friction in midlatitude cyclones. Quart. J. Roy. Meteor. Soc., 132, 101-124, https://doi.org/10.1256/qj.04.145.
Bechtold, P., M. Köhler, T. Jung, F. Doblas-Reyes, M. Leutbecher, M. J. Rodwell, F. Vitart, and G. Balsamo, 2008: Advances in simulating atmospheric variability with the ECMWF model: From synoptic to decadal time-scales. Quart. J. Roy. Meteor. Soc., 134, 1337-1351, https://doi.org/10.1002/qj.289.

Beljaars, A. C. M., A. R. Brown, and N. Wood, 2004: A new parametrization of turbulent orographic form drag. Quart. J. Roy. Meteor. Soc., 130, 1327-1347, https://doi.org/10.1256/ qj.03.73.

Birner, T., A. Dörnbrack, and U. Schumann, 2002: How sharp is the tropopause at midlatitudes? Geophys. Res. Lett., 29, 1700 , https://doi.org/10.1029/2002GL015142.

Browning, K. A., 1986: Conceptual models of precipitation systems. Wea. Forecasting, 1, 23-41, https://doi.org/10.1175/15200434(1986)001<0023:CMOPS>2.0.CO;2.

Büeler, D., and S. Pfahl, 2017: Potential vorticity diagnostics to quantify effects of latent heating in extratropical cyclones. Part I: Methodology. J. Atmos. Sci., 74, 3567-3590, https:// doi.org/10.1175/JAS-D-17-0041.1.

Cau, P., J. Methven, and B. Hoskins, 2005: Representation of dry tropical layers and their origins in ERA-40 data. J. Geophys. Res., 110, D06110, https://doi.org/10.1029/2004JD004928.

Cavallo, S. M., and G. J. Hakim, 2012: Radiative impact on tropopause polar vortices over the Arctic. Mon. Wea. Rev., 140, 1683-1702, https://doi.org/10.1175/MWR-D-11-00182.1.

Chagnon, J. M., and S. L. Gray, 2015: A diabatically generated potential vorticity structure near the extratropical tropopause in three simulated extratropical cyclones. Mon. Wea. Rev., 143, 2337-2347, https://doi.org/10.1175/MWR-D-14-00092.1. , - - and J. Methven, 2013: Diabatic processes modifying potential vorticity in a North Atlantic cyclone. Quart. J. Roy. Meteor. Soc., 139, 1270-1282, https://doi.org/10.1002/qj.2037.

Crezee, B., H. Joos, and H. Wernli, 2017: The microphysical building blocks of low-level potential vorticity anomalies in an idealized extratropical cyclone. J. Atmos. Sci., 74, 1403-1416, https://doi.org/10.1175/JAS-D-16-0260.1.

Davies, H. C., and A. M. Rossa, 1998: PV frontogenesis and uppertropospheric fronts. Mon. Wea. Rev., 126, 1528-1539, https:// doi.org/10.1175/1520-0493(1998)126<1528:PFAUTF> 2.0.CO;2.

Davis, C. A., and K. A. Emanuel, 1991: Potential vorticity diagnostics of cyclogenesis. Mon. Wea. Rev., 119, 1929-1953, https://doi.org/10.1175/1520-0493(1991)119<1929:PVDOC> 2.0.CO;2.

Dearden, C., G. Vaughan, T. Tsai, and J.-P. Chen, 2016: Exploring the diabatic role of ice microphysical processes in two North Atlantic summer cyclones. Mon. Wea. Rev., 144, 1249-1272, https://doi.org/10.1175/MWR-D-15-0253.1.

Dyroff, C., A. Zahn, E. Christner, R. Forbes, A. M. Tompkins, and P. F. J. van Velthoven, 2015: Comparison of ECMWF analysis and forecast humidity data with CARIBIC upper troposphere and lower stratosphere observations. Quart. J. Roy. Meteor. Soc., 141, 833-844, https://doi.org/10.1002/qj.2400.

ECMWF, 2016a: IFS documentation-Cy43r1: Operational implementation 22 Nov 2016. Part III: Dynamics and numerical procedures. ECMWF Rep., 31 pp., https://www.ecmwf.int/en/ elibrary/17116-part-iii-dynamics-and-numerical-procedures.

_- 2016b: IFS documentation-Cy43r1: Operational implementation 22 Nov 2016. Part IV: Physical processes. ECMWF Rep., 223 pp., https://www.ecmwf.int/en/elibrary/ 17117-part-iv-physical-processes.

Ertel, H., 1942: Ein neuer hydrodynamischer Wirbelsatz. Meteor. Z., 9, 271-281. 
Ferreira, A. P., J. M. Castanheira, and L. Gimeno, 2016: Water vapour stratification and dynamical warming behind the sharpness of the Earth's midlatitude tropopause. Quart. J. Roy. Meteor. Soc., 142, 957-970, https://doi.org/10.1002/qj.2697.

Forbes, R., and A. Tompkins, 2011: An improved representation of cloud and precipitation. ECMWF Newsletter, No. 129 , ECMWF, Reading, United Kingdom, 13-18, https://doi.org/ 10.21957/nfgulzhe.

— , and M. Ahlgrimm, 2014: On the representation of highlatitude boundary layer mixed-phase cloud in the ECMWF global model. Mon. Wea. Rev., 142, 3425-3445, https://doi.org/ 10.1175/MWR-D-13-00325.1.

Forster, C., and V. Wirth, 2000: Radiative decay of idealized stratospheric filaments in the troposphere. J. Geophys. Res. 105, 10169-10 184, https://doi.org/10.1029/2000JD900052.

Gidel, L. T., and M. A. Shapiro, 1979: The role of clear air turbulence in the production of potential vorticity in the vicinity of upper tropospheric jet stream-frontal systems. J. Atmos. Sci., 36, 2125-2138, https://doi.org/10.1175/1520-0469(1979)036<2125: TROCAT $>2.0 . C O ; 2$.

Grams, C. M., and Coauthors, 2011: The key role of diabatic processes in modifying the upper-tropospheric wave guide: A North Atlantic case-study. Quart. J. Roy. Meteor. Soc., 137, 2174-2193, https://doi.org/10.1002/qj.891.

Gray, S. L., 2006: Mechanisms of midlatitude cross-tropopause transport using a potential vorticity budget approach. J. Geophys. Res., 111, D17113, https://doi.org/10.1029/ 2005JD006259.

— C. M. Dunning, J. Methven, G. Masato, and J. M. Chagnon, 2014: Systematic model forecast error in Rossby wave structure. Geophys. Res. Lett., 41, 2979-2987, https://doi.org/ 10.1002/2014GL059282.

Hardy, S., D. M. Schultz, and G. Vaughan, 2017: Early evolution of the 23-26 September 2012 U.K. floods: Tropical storm Nadine and diabatic heating due to cloud microphysics. Mon. Wea. Rev., 145, 543-563, https://doi.org/10.1175/MWR-D16-0200.1.

Hartjenstein, G., 2000: Diffusive decay of tropopause folds and the related cross-tropopause mass flux. Mon. Wea. Rev., 128, 2958-2966, https://doi.org/10.1175/1520-0493(2000)128<2958: DDOTFA $>2.0 . \mathrm{CO} ; 2$.

Hoskins, B. J., M. E. McIntyre, and A. W. Robertson, 1985: On the use and significance of isentropic potential vorticity maps. Quart. J. Roy. Meteor. Soc., 111, 877-946, https:// doi.org/10.1002/qj.49711147002.

Iacono, M. J., J. S. Delamere, E. J. Mlawer, M. W. Shephard, S. A. Clough, and W. D. Collins, 2008: Radiative forcing by longlived greenhouse gases: Calculations with the AER radiative transfer models. J. Geophys. Res., 113, D13103, https://doi.org/ 10.1029/2008JD009944.

Igel, A. L., and S. C. van den Heever, 2014: The role of latent heating in warm frontogenesis. Quart. J. Roy. Meteor. Soc., 140, 139-150, https://doi.org/10.1002/qj.2118.

Jaeger, E. B., and M. Sprenger, 2007: A Northern Hemispheric climatology of indices for clear air turbulence in the tropopause region derived from ERA40 reanalysis data. J. Geophys. Res., 112, D20106, https://doi.org/10.1029/ 2006JD008189.

Joos, H., and H. Wernli, 2012: Influence of microphysical processes on the potential vorticity development in a warm conveyor belt: A case-study with the limited-area model COSMO. Quart. J. Roy. Meteor. Soc., 138, 407-418, https://doi.org/ 10.1002/qj.934.
— , and R. M. Forbes, 2016: Impact of different IFS microphysics on a warm conveyor belt and the downstream flow evolution. Quart. J. Roy. Meteor. Soc., 142, 2727-2739, https://doi.org/10.1002/qj.2863.

Köhler, M., M. Ahlgrimm, and A. Beljaars, 2011: Unified treatment of dry convective and stratocumulus-topped boundary layers in the ECMWF model. Quart. J. Roy. Meteor. Soc., 137, 43-57, https://doi.org/10.1002/qj.713.

Kunkel, D., P. Hoor, and V. Wirth, 2016: The tropopause inversion layer in baroclinic life-cycle experiments: The role of diabatic processes. Atmos. Chem. Phys., 16, 541-560, https://doi.org/ 10.5194/acp-16-541-2016.

Lackmann, G. M., 2002: Cold-frontal potential vorticity maxima, the low-level jet, and moisture transport in extratropical cyclones. Mon. Wea. Rev., 130, 59-74, https://doi.org/10.1175/ 1520-0493(2002)130<0059:CFPVMT >2.0.CO;2.

Lamarque, J.-F., and P. G. Hess, 1994: Cross-tropopause mass exchange and potential vorticity budget in a simulated tropopause folding. J. Atmos. Sci., 51, 2246-2269, https://doi.org/ 10.1175/1520-0469(1994)051<2246:CTMEAP>2.0.CO;2.

Lang, A. A., and J. E. Martin, 2012: The structure and evolution of lower stratospheric frontal zones. Part 1: Examples in northwesterly and southwesterly flow. Quart. J. Roy. Meteor. Soc., 138, 1350-1365, https://doi.org/10.1002/qj.843.

Leutbecher, M., and Coauthors, 2017: Stochastic representations of model uncertainties at ECMWF: State of the art and future vision. Quart. J. Roy. Meteor. Soc., 143, 2315-2339, https:// doi.org/10.1002/qj.3094.

Lott, F., and M. J. Miller, 1997: A new subgrid-scale orographic drag parametrization: Its formulation and testing. Quart. J. Roy. Meteor. Soc., 123, 101-127, https://doi.org/10.1002/ qj.49712353704.

Madonna, E., H. Wernli, H. Joos, and O. Martius, 2014: Warm conveyor belts in the ERA-Interim dataset (1979-2010). Part I: Climatology and potential vorticity evolution. J. Climate, 27, 3-26, https://doi.org/10.1175/JCLI-D-12-00720.1.

Martius, O., C. Schwierz, and H. C. Davies, 2010: Tropopause-level waveguides. J. Atmos. Sci., 67, 866-879, https://doi.org/10.1175/ 2009JAS2995.1.

Mlawer, E. J., S. J. Taubman, P. D. Brown, M. J. Iacono, and S. A. Clough, 1997: Radiative transfer for inhomogeneous atmospheres: RRTM, a validated correlated-k model for the longwave. J. Geophys. Res., 102, 16 663-16682, https://doi.org/ 10.1029/97JD00237.

Morcrette, J.-J., H. W. Barker, J. N. S. Cole, M. J. Iacono, and R. Pincus, 2008: Impact of a new radiation package, McRad, in the ECMWF Integrated Forecasting System. Mon. Wea. Rev., 136, 4773-4798, https://doi.org/10.1175/2008MWR2363.1.

Orr, A., P. Bechtold, J. Scinocca, M. Ern, and M. Janiskova, 2010: Improved middle atmosphere climate and forecasts in the ECMWF model through a nonorographic gravity wave drag parameterization. J. Climate, 23, 5905-5926, https://doi.org/ 10.1175/2010JCLI3490.1.

Parker, D. J., and A. J. Thorpe, 1995: The role of snow sublimation in frontogenesis. Quart. J. Roy. Meteor. Soc., 121, 763-782, https://doi.org/10.1002/qj.49712152403.

Plougonven, R., and F. Zhang, 2014: Internal gravity waves from atmospheric jets and fronts. Rev. Geophys., 52, 33-76, https:// doi.org/10.1002/2012RG000419.

Pomroy, H. R., and A. J. Thorpe, 2000: The evolution and dynamical role of reduced upper-tropospheric potential vorticity in intensive observing period one of FASTEX. Mon. Wea. Rev., 128, 1817-1834, https://doi.org/10.1175/1520-0493(2000) $128<1817$ :TEADRO $>2.0$. CO 2 . 
Reid, H. J., and G. Vaughan, 2004: Convective mixing in a tropopause fold. Quart. J. Roy. Meteor. Soc., 130,1195-1212, https:// doi.org/10.1256/qj.03.21.

Rossa, A. M., H. Wernli, and H. C. Davies, 2000: Growth and decay of an extra-tropical cyclone's PV-tower. Meteor. Atmos. Phys., 73, 139-156, https://doi.org/10.1007/s007030050070.

Saffin, L., J. Methven, and S. L. Gray, 2016: The non-conservation of potential vorticity by a dynamical core compared with the effects of parametrized physical processes. Quart. J. Roy. Meteor. Soc., 142, 1265-1275, https://doi.org/10.1002/qj.2729.

_ , S. L. Gray, J. Methven, and K. D. Williams, 2017: Processes maintaining tropopause sharpness in numerical models. J. Geophys. Res. Atmos., 122, 9611-9627, https://doi.org/ 10.1002/2017JD026879.

Shapiro, M. A., 1976: The role of turbulent heat flux in the generation of potential vorticity in the vicinity of upper-level jet stream systems. Mon. Wea. Rev., 104, 892-906, https://doi.org/ 10.1175/1520-0493(1976)104<0892:TROTHF>2.0.CO;2.

, 1978: Further evidence of the mesoscale and turbulent structure of upper level jet stream-frontal zone systems. Mon. Wea. Rev., 106, 1100-1111, https://doi.org/10.1175/1520-0493(1978) 106<1100:FEOTMA $>2.0$.CO;2.

_ 1980: Turbulent mixing within tropopause folds as a mechanism for the exchange of chemical constituents between the stratosphere and troposphere. J. Atmos. Sci., 37, 994-1004, https://doi.org/10.1175/1520-0469(1980)037<0994:TMWTFA > 2.0.CO;2.

Siebesma, A. P., P. M. M. Soares, and J. Teixeira, 2007: A combined eddy-diffusivity mass-flux approach for the convective boundary layer. J. Atmos. Sci., 64, 1230-1248, https://doi.org/ 10.1175/JAS3888.1.

Sprenger, M., and H. Wernli, 2015: The LAGRANTO Lagrangian analysis tool-Version 2.0. Geosci. Model Dev., 8, 2569-2586, https://doi.org/10.5194/gmd-8-2569-2015.

, M. C. Maspoli, and H. Wernli, 2003: Tropopause folds and cross-tropopause exchange: A global investigation based upon ECMWF analyses for the time period March 2000 to February 2001. J. Geophys. Res., 108, D12108, https://doi.org/10.1029/ 2002JD002587.

Staley, D. O., 1960: Evaluation of potential-vorticity changes near the tropopause and the related vertical motions, vertical advection of vorticity, and transfer of radioactive debris from stratosphere to troposphere. J. Meteor., 17, 591-620,
https://doi.org/10.1175/1520-0469(1960)017<0591:EOPVCN> 2.0.CO;2.

Stoelinga, M. T., 1996: A potential vorticity-based study of the role of diabatic heating and friction in a numerically simulated baroclinic cyclone. Mon. Wea. Rev., 124, 849-874, https:// doi.org/10.1175/1520-0493(1996)124<0849:APVBSO > 2.0. $\mathrm{CO} ; 2$.

Stohl, A., and Coauthors, 2003: Stratosphere-troposphere exchange: A review, and what we have learned from STACCATO.J. Geophys. Res., 108, 8516, https://doi.org/ 10.1029/2002JD002490.

Tiedtke, M., 1989: A comprehensive mass flux scheme for cumulus parameterization in large-scale models. Mon. Wea. Rev., 117, 17791800, https://doi.org/10.1175/1520-0493(1989)117<1779:ACMFSF> 2.0.CO;2.

_ 1993: Representation of clouds in large-scale models. Mon. Wea. Rev., 121, 3040-3061, https://doi.org/10.1175/1520-0493(1993) $121<3040:$ ROCILS $>2.0$. CO; 2 .

Tory, K. J., J. D. Kepert, J. A. Sippel, and C. M. Nguyen, 2012: On the use of potential vorticity tendency equations for diagnosing atmospheric dynamics in numerical models. J. Atmos. Sci., 69, 942-960, https://doi.org/10.1175/JASD-10-05005.1.

Vannière, B., A. Czaja, H. Dacre, T. Woollings, and R. Parfitt, 2016: A potential vorticity signature for the cold sector of winter extratropical cyclones. Quart. J. Roy. Meteor. Soc., 142 , 432-442, https://doi.org/10.1002/qj.2662.

Viterbo, P., and A. C. M. Beljaars, 1995: An improved land surface parameterization scheme in the ECMWF model and its validation. J. Climate, 8, 2716-2748, https://doi.org/10.1175/15200442(1995)008<2716:AILSPS>2.0.CO;2.

Wernli, H., and H. C. Davies, 1997: A Lagrangian-based analysis of extratropical cyclones. I: The method and some applications. Quart. J. Roy. Meteor. Soc., 123, 467-489, https://doi.org/ 10.1002/qj.49712353811.

Wirth, V., and J. Egger, 1999: Diagnosing extratropical synopticscale stratosphere-troposphere exchange: A case study. Quart. J. Roy. Meteor. Soc., 125, 635-655, https://doi.org/10.1002/ qj. 49712555413.

Zierl, B., and V. Wirth, 1997: The influence of radiation on tropopause behavior and stratosphere-troposphere exchange in an upper tropospheric anticyclone. J. Geophys. Res., 102, 23 883-23 894, https://doi.org/10.1029/97JD01667. 